Aus der Abteilung Vegetative Physiologie und Pathophysiologie (Prof. Dr. med. G. Burckhardt) im Zentrum Physiologie und Pathophysiologie der Medizinischen Fakultät der Universität Göttingen

\title{
Interaktionen von Diuretika mit dem humanen Natrium-abhängigen Dikarboxylat-Transporter (hNaDC-3)
}

\author{
Inaugural-Dissertation \\ zur Erlangung des Doktorgrades \\ der Medizinischen Fakultät \\ der Georg-August-Universität zu Göttingen \\ vorgelegt von \\ Ingo Sebastian Müller \\ aus \\ Marburg
}

Göttingen 2011 
Dekan:

I. Berichterstatterin:

II. Berichterstatter/in:
Prof. Dr. med. C. Frömmel

Prof. Dr. phil. nat. B. C. Burckhardt

Priv-Doz. Dr. med. Vormfelde

Tag der mündlichen Prüfung: 24. Oktober 2011 


\section{Inhaltsverzeichnis}

1 Einleitung

1.1 Schleifendiuretika

1.1.1 Eigenschaften von Schleifendiuretika ___ 3

1.1.2 Anwendung von Schleifendiuretika in der Pharmakotherapie ___ 6

1.1.3 Nebenwirkungen der Schleifendiuretika _ 7

1.1.4 Wichtigste Kontraindikationen und Interaktionen 2

1.2 Transportsysteme in der Tubuluszelle __ 8

1.2.1 Organische Anionentransporter (OATs) __ 8

1.2.2 $\mathrm{Na}^{+}$-abhängige Dikarboxylat-Cotransporter (NaDCs) _ 10

1.3 Zielsetzung _ 12

2 Material und Methoden __ 16

2.1 Entnahme und Präparation der Oozyten__ 16

2.1.1 Oozyten des Xenopus laevis___ 16

2.1.2 Entnahme der Oozyten ___ 17

2.1.3 Injektion der Oozyten mit cRNA___ 18

2.2 Die elektrophysiologische Messung __ 19

2.2.1 Messplatz___ 19

2.2.2 Registrierung der Messwerte____ 21

2.2.3 Vorbereitung der Mikroelektroden___ 21

2.2.4 Messung mit der Zwei-Elektroden-Spannungsklemm-Technik___ 21

2.3 Transportmessungen mit radioaktiv-markiertem Substrat ___ 24

2.4 Lösungen und Chemikalien $\_24$

2.4.1 Zusammensetzung der Kontrolllösung ORi__ 24

2.4.2 Zusatzstoffe für die Aufbewahrungslösung der Oozyten__ 25

2.4.3 Molekulargewichte der getesteten Substanzen__ 25

2.4.4 Testsubstanzen _ 25

2.4.5 Herkunft der verwendeten Chemikalien 26

2.5 Geräteliste _ـ 27 
3.1 Interaktion von Succinat mit dem hNaDC-3

3.2 Wechselwirkungen von Furosemid und Succinat mit dem hNaDC-3

3.2.1 Hemmung der $\left[{ }^{14} \mathrm{C}\right]$ Succinat-Aufnahme durch Furosemid 31

3.2.2 Hemmung des Succinat-induzierbaren Stromes durch Furosemid 32

3.2.3 Einfluss aufsteigender Furosemidkonzentrationen auf den Succinat 34 induzierbaren Strom 34

3.3 Translokation von Furosemid über den hNaDC-3 36

3.3.1 Natriumabhängigkeit des Furosemid-induzierbaren Stromes 38

3.3.2 Interaktionen von Lithium und Furosemid

3.4 Interaktion von Bumetanid mit dem hNaDC-3 41

3.5 Interaktion von Etacrynsäure mit dem hNaDC-3 43

3.6 Interaktion von Acetazolamid und Sulfanilamid mit dem hNaDC-3 44

4 Diskussion 46

4.1 Interaktion von Schleifendiuretika mit dem hNaDC-3 46

4.2 Wirkung von Lithium auf den hNaDC-3 50

5 Zusammenfassung 51

6 Literaturverzeichnis 


\section{Einleitung}

\subsection{Schleifendiuretika}

\subsubsection{Eigenschaften von Schleifendiuretika}

Diuretika sind harntreibende Mittel, deren harntreibender Effekt durch die renale Ausscheidung von Salzen, die osmotisch Wasser binden, zu Stande kommt. Besonders wichtig ist in diesem Zusammenhang der Transport von Natrium durch das Tubulusepithel der Nieren. Außer Osmodiuretika und Xanthinen greifen alle Diuretika direkt an den Transportproteinen für Natrium in der luminalen Membran der Tubuluszelle an und steigern dadurch die renale Natrium- und Wasserausscheidung. Diuretika erreichen eine hohe Organspezifität, da sie durch Wasserresorption und tubuläre Sekretion im Lumen des Nephrons konzentriert werden.

Eine besonders wirksame Gruppe von Diuretika sind die Schleifendiuretika (wie z.B. Furosemid, Torasemid, Bumetanid und Etacrynsäure). Sie erzielen ihre Wirkung durch eine reversible Bindung an der $\mathrm{Cl}^{-}$-Bindungsstelle des im aszendierenden Teil der Henle-Schleife lokalisierten $\mathrm{Na}^{+}-\mathrm{K}^{+}-2 \mathrm{Cl}^{-}$-Cotransporters (GECK et al. 1980, GREGER und SCHLATTER 1983, GREGER 2000). Dadurch wird der Rücktransport von Natrium über die luminale Membran der Tubuluszelle vermindert und es kommt zu einer erhöhten Ausscheidung von Natrium, Kalium und Chlorid, was eine erhöhte Ausscheidung von Wasser nach sich führt (WANG $\mathrm{H}$ et al. 2000, SHANKAR und BRATER 2003, BAGSHAW et al. 2008). Schematisch dargestellt ist die Wirkung von Furosemid in Abbildung 1. Der durch Schleifendiuretika hervorgerufene gesteigerte Harnfluss, kann bei entsprechender Flüssigkeitssubstitution bis zu 45 L/d erreichen. Des Weiteren kommt es zu einem Zusammenbruch der lumenpositiven transepithelialen elektrischen Potenzialdifferenz und folglich zu einer Einschränkung der Resorption von $\mathrm{Ca}^{2+}$ und $\mathrm{Mg}^{2+}$. Ein weiterer Effekt der Schleifendiuretika ist die Verminderung des Bedarfs an metabolischen Substituenten und Sauerstoff. Furosemid führt so zu einem Schutz bei hypoxischen Nierenschäden. Darüber hinaus hemmen Schleifendiuretika die Aufnahme von Natrium, Kalium und Chlorid in 
die Zellen der Macula densa, wodurch der tubuloglomeruläre Feedback unterbrochen wird (GREGER 1997, KIIL 2002, WILCOX 2002).

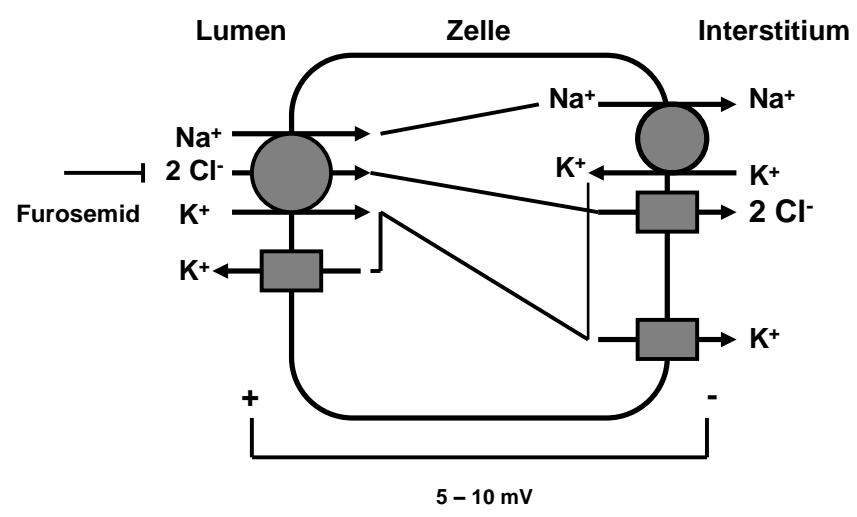

Abbildung 1: Schema des Elektrolyttransportes im dicken aszendierenden Schenkel der Henle - Schleife. Von den über den luminalen $\mathrm{Na}^{+}-\mathrm{K}^{+}-2 \mathrm{Cl}^{-}$- Cotransporter aufgenommenen Elektrolyten wird $\mathrm{K}^{+}$wieder durch $\mathrm{K}^{+}$- selektive Kanäle in das Lumen rezirkuliert, wodurch die lumenpositive, transepitheliale elektrische Potenzialdifferenz entsteht. Ein weiterer Teil des $\mathrm{K}^{+}$verlässt die Zelle über basolaterale $\mathrm{K}^{+}$- Kanäle. $\mathrm{Cl}^{-}$wird über $\mathrm{Cl}^{-}$Kanäle in das Interstitium abgegeben. Der $\mathrm{Na}^{+}-\mathrm{K}^{+}-2 \mathrm{Cl}^{-}$- Cotransporter wird durch Schleifendiuretika, z.B. Furosemid, gehemmt.

Der durch die Schleifendiuretika zu erzielende Effekt setzt sehr schnell ein (nach peroraler Gabe innerhalb von 30-60 Minuten und nach intravenöser Zufuhr ca. nach 15 Minuten), hält allerdings nur 4-5 h an. Anschließend kommt es zu einem Rückfall auf die vor der Diuretikagabe gemessenen Werte.

Die Organspezifität der Schleifendiuretika kommt durch ihre hohe Konzentration im tubulären Lumen, der deutlich über der freien Konzentration im Plasma liegt, zustande (GREGER 1988). Diese starke Konzentration wird dadurch erreicht, dass die Schleifendiuretika auf Grund ihrer hohen Bindung an Plasmaproteine (über 95\%) so gut wie gar nicht glomerulär filtriert werden (SHANKAR und BRATER 2003), sondern das tubuläre Lumen durch Sekretion im proximalen Tubulus erreichen. 


\begin{tabular}{|l|l|l|}
\hline Freiname & Mittlere Tagesdosis & Wirkdauer $(\mathrm{h})$ \\
\hline Bumetanid & $0,5-2 \mathrm{mg}$ & $4-5$ \\
\hline Etacrynsäure & $50-150 \mathrm{mg}$ & $6-8$ \\
\hline Furosemid & $40-80 \mathrm{mg}$ & $4-5$ \\
\hline Torasemid & $2,5-20 \mathrm{mg}$ & $5-6$ \\
\hline
\end{tabular}

Tabelle 1: Übersicht über die am häufigsten eingesetzten Schleifendiuretika, ihre Handelsnamen, die mittlere Tagesdosis und ihre Wirkdauer (FÜLGRAFF und PALM 2001)

Leitsubstanz der Schleifendiuretika ist Furosemid. Furosemid ist ein Sulfamylbenzenderivat der Anthranilsäure mit der chemischen Bezeichnung 4-Chlor$\mathrm{N}$-(2-furylmethyl)-5-sulfamoylanthranilsäure. Die wichtigsten Strukturmerkmale sind eine Carboxylgruppe und die Sulfonamidstruktur.

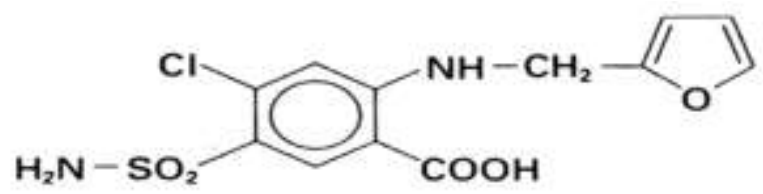

Furosemid

Abbildung 2: Darstellung der Strukturformel von Furosemid

Der pKa von Furosemid liegt bei 3,9, der Schmelzpunkt bei $206^{\circ} \mathrm{C}$ und das Molekulargewicht beträgt 330,7 g/mol. Furosemid kommt in Form eines weissgelblichen, kristallinen Pulvers vor, welches geruch- und praktisch geschmacklos ist. Es ist schlecht wasserlöslich (PONTO und SCHOENWALD 1990).

In Abbildung 3 sind die Strukturformeln des Furosemid-verwandten Bumetanid und der Etacrynsäure dargestellt. Letztere ist im Gegensatz zu den anderen Schleifendiuretika eine halogenierte Phenoxyessigsäure. 


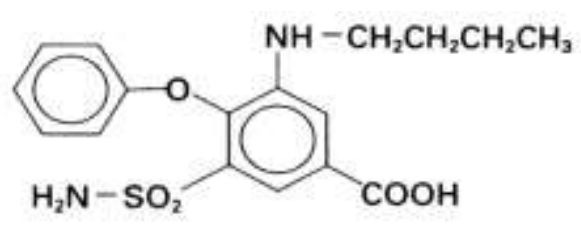

Bumetanid<smiles>C=C(CC)C(=O)c1ccc(OCC(=O)O)c(Cl)c1Cl</smiles>

Etacrynsäure

Abbildung 3: Strukturformeln von Bumetanid und Etacrynsäure

\subsubsection{Anwendung von Schleifendiuretika in der Pharmakotherapie}

Klassischer Anwendungsbereich für Schleifendiuretika ist die akute kardiale Dekompensation. Ziel der diuretischen Therapie ist es, die Volumenbelastung des Herzens zu verringern, den linksventrikulären Druck zu senken und die Oxygenierung des Blutes durch Beseitigung der pulmonalen Stauung zu verbessern. Ein weiterer Effekt der Schleifendiuretika ist die Reduzierung der Vorlast durch eine Erweiterung der Kapazitätsgefäße, sowie die Steigerung, der bei einer Herzinsuffizienz gesenkten, glomerulären Filtrationsrate (KAPOOR und PERAZELLA 2007,WANG D und GOTTLIEB 2008, AKIN et al. 2009, JOSEPH et al. 2009).

Des Weiteren kommen Schleifendiuretika in der Behandlung des durch Leberzirrhose bedingten Aszites zur Anwendung (GERBES und GÜLBERG 2004). Bei dieser Kombination muss allerdings besonders auf Entgleisungen des Elektrolythaushaltes geachtet werden, da die Patienten diese, bedingt durch die Leberzirrhose, besonders schlecht ausgleichen können.

Furosemid wird darüber hinaus in der Therapie des akuten Nierenversagens (ANV) eingesetzt. Hierbei wirkt es durch eine mögliche Durchbrechung der Oligurie und erleichtert das Flüssigkeits- und Elektrolytmanagement. Eine Verringerung der Mortalität oder eine Prognoseverbesserung durch die Furosemidtherapie bei ANV konnte bisher nicht nachgewiesen werden (LAMEIRE et al. 2002, SAMPATH et al. 2007).

Die durch Schleifendiuretika hervorgerufene erhöhte Kalziumausscheidung wird mittlerweile als vernachlässigbar betrachtet und es wird daher empfohlen, Diuretika 
zur Behandlung der Hyperkalziämie nur bei gleichzeigt erwünschtem diuretischen Effekt zu verwenden (RALSTON et al. 2004, LEGRAND et al. 2008).

Auch ein protektiver Effekt, sowohl gegen Belastungsasthma als auch gegen das exogen-allergen ausgelöste Asthma, wird der inhalativen Einnahme von Furosemid zugeschrieben (BIANCO et al 1988, BHURE et al. 2009).

\subsubsection{Nebenwirkungen der Schleifendiuretika}

Eine der häufigsten Nebenwirkungen der Schleifendiuretika ist die dosisabhängige Hypokaliämie durch einen verstärkten renalen $\mathrm{K}^{+}$-Verlust (BRATER 1998). Die Konsequenzen einer Hypokaliämie sind Muskelschwäche und Obstipation, Hyperglykämie oder Störung der Glucosetoleranz, sowie eine Zunahme der ektopen Rhythmusaktivität des Herzens. Besonders groß ist die Gefahr für ektope Rhythmusaktivitäten bei einer gleichzeitig bestehenden Hypomagnesiämie, welche ebenfalls durch Schleifendiuretika hervorgerufen werden kann.

Die durch Schleifendiuretika verursachte Hyponatriämie kann ein limitierender Faktor für die lang anhaltende und hoch dosierte Therapie mit Schleifendiuretika sein. Die durch Schleifendiuretika hervorgerufenen Volumenänderungen und Elektrolytverschiebungen aktivieren zudem das sympathoadrenale System. Dadurch kommt es zu einer Sekretion von Renin und in Folge davon zu einer erhöhten Freisetzung von Aldosteron und Vasopressin, was zu einer Abnahme des diuretischen Effektes führt.

Bei Patienten mit reduziertem effektivem zirkulierenden Volumen (Patienten mit Herzinsuffizienz, Leberzirrhose, Nierenschäden oder Patienten mit hohem Lebensalter) kann der Flüssigkeitsverlust zum Blutdruckabfall und verminderter Durchblutung einzelner Organe führen.

Eine gefürchtete Nebenwirkung von Furosemid ist die Ototoxzität bei Verabreichung von höheren Dosierungen. Hierbei kann es zu Hörstörungen in unterschiedlichen Schweregraden bis hin zum permanenten Hörverlust kommen (WANG D und GOTTLIEB 2008). Deshalb ist bei einer gleichzeitigen Gabe von ototoxischen 
Antibiotika (z.B. Makrolide bzw. Cisplatin) besondere Vorsicht geboten. Durch die verstärkte $\mathrm{Ca}^{2+}$-Ausscheidung sind Schleifendiuretika bei Osteoporose-gefährdeten Patienten in der Langzeittherapie nur mit Vorsicht anzuwenden.

\subsubsection{Wichtigste Kontraindikationen und Interaktionen}

Nicht angewendet werden sollten Schleifendiuretika bei schweren Elektrolytstörungen, Hypokaliämie oder Hyponatriämie. Bei der gleichzeitigen Anwendung von Schleifendiuretika und Digitalispräparaten ist auf Grund der kaliumsenkenden Wirkung von Schleifendiuretika mit einer erhöhten Toxizität von Digitalispräparaten zu rechnen. Lithium kann bei gleichzeitiger Einnahme von Schleifendiuretika toxische Plasmawerte im Körper erreichen. Schleifendiuretika erhöhen bei gleichzeitiger Gabe von nicht-steroidalen Antiphlogistika das Risiko für eine Nierenschädigung (HO und POWER 2010). In der Schwangerschaftszeit und Stillzeit ist von einer Schleifendiuretikagabe abzusehen.

\subsection{Transportsysteme in der Tubuluszelle}

\subsubsection{Organische Anionentransporter (OATs)}

Auf Grund ihrer hohen Eiweißbindung (s.o.) spielt die tubuläre Sekretion für Schleifendiuretika und Thiaziddiuretika eine besonders große Rolle, um eine ausreichende Anreicherung im Tubuluslumen zu erzielen. Für diesen Prozess der Sekretion durch einen unidirektionalen transzellulären Transport von der Aufnahme der organischen Anionen aus dem Blut über die basolaterale Membran und anschließend über die luminale Bürstensaummembran in das Lumen des proximalen Tubulus spielen in der proximalen Tubuluszelle gelegene organische Anionentransporter (OATs) eine entscheidende Rolle (PONTO und SCHOENWALD 1990, DRESSER et al. 2001, SHANKAR und BRATER 2003, HASANNEJAD et al. 2004).

Erste Funktionsbeschreibungen dieser Transporter gelangen durch Versuche an Nierenschnitten und Vesikelpräparationen aus der basolateralen Membran proximaler Tubuluszellen, sowie durch Versuche an der Rattenniere in situ 
(Übersichtsarbeiten: ULLRICH und RUMRICH 1988, PRITCHARD und MILLER 1991, PRITCHARD und MILLER 1993, ULLRICH und RUMRICH 1993, ULLRICH 1994, ULLRICH 1997, KOJIMA et al. 2002).

Mittlerweile konnten von der Familie der organischen Anionentransporter (OATs) 10 verschiedene Mitglieder kloniert und charakterisiert werden. (Übersichtsarbeiten: , BURCKHARDT BC und BURCKHARDT G 2003, ANZAl et al. 2005, ANZAl et al. 2006, ROBERTSON und RANKIN 2006, RIZWAN und BURCKHARDT G 2007, BAHN et al. 2008, WARGO und BANTA 2009, SEKINE und ENDOU 2009). In der menschlichen Niere sind besonders der in der apikalen Seite des proximalen Tubulus gelegene hOAT4 (BABU et al. 2002) und die in der basolateralen Membran des proximalen Tubulus befindlichen hOAT1 und hOAT3 exprimiert (HOSOYAMADA et al. 1999, CHA et al. 2001, KIMURA et al. 2002, KOBAYASHI et al. 2005).

Für den basolateralen transmembranalen Transport der Thiazide scheint der hOAT1 zuständig zu sein, wohingegen Schleifendiuretika über den hOAT3 in das Zellinnere transportiert werden. Allerdings werden durch den hOAT1 auch die Schleifendiuretika Bumetanid und Furosemid in geringem Maße transportiert. Der Transport der Diuretika über die luminale Membran der Tubuluszellen in den Urin, scheint über den in der luminalen Membran gelegenen hOAT4 zu geschehen (HASANNEJAD et al. 2004).

Das eigentliche klassische Substrat der OATs ist $p$-Aminohippurat (PAH). Der Transport des organischen Anions PAH über die basolaterale Membran geschieht im Austausch gegen ein intrazelluläres Dikarboxylat, vorzugsweise $\alpha$-Ketoglutarat, im Verhältnis von 1:1 über den OAT1 und/oder den OAT3 (Übersichtsarbeiten in: BURCKHARDT BC und BURCKHARDT G 2003, DANTZLER und WRIGHT 2003, KOEPSELL und ENDOU 2004, ANZAl et al. 2006). Um zu gewährleisten, dass jederzeit genug $\alpha$ - Ketoglutarat in der Zelle zur Verfügung steht, wird u.a. durch die zum einen in der luminalen Bürstensaum-Membran und zum anderen in der basolateralen Membran des proximalen Tubulus lokalisierten Natrium-abhängigen Dikarboxylat-Cotransporter (NaDCs) im Symport mit 3 Natrium-Ionen $\alpha$ - Ketoglutarat in die Zelle aufgenommen (MARKOVICH und MURER 2004, OSHIRO und PAJOR 2005). 
Ein Modell dieser beschriebenen Transportprozesse der proximalen Tubuluszelle ist in Abbildung 4 dargestellt.

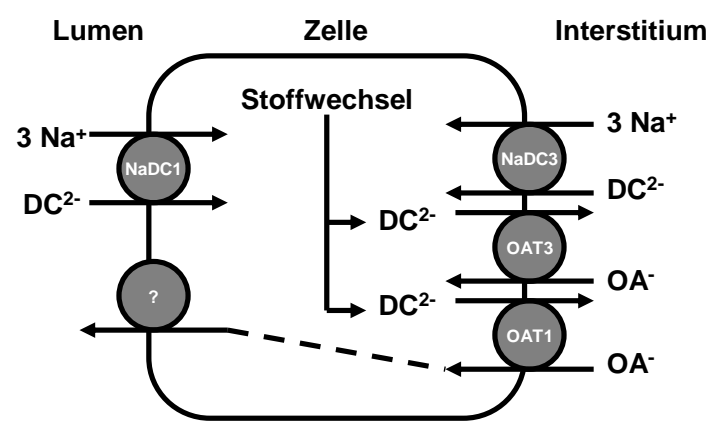

Abbildung 4: Das Schema stellt die verschiedenen bisher bekannten Transportsysteme der proximalen Tubuluszelle der Niere in vereinfachter Form dar. Ein Substrat des in der basolateralen Membran lokalisierten NaDC-3 ist das Dikarboxylat $\left(\mathrm{DC}^{2-}\right) \alpha$ - Ketoglutarat, welches im Symport mit 3 Natrium-lonen in die Zelle transportiert wird. $\alpha$-Ketoglutarat wird als Substrat für die ebenfalls in der basolateralen Membran gelegenen Transportsysteme OAT 1 bzw. OAT 3 verwendet. Triebkraft dieser Vorgänge ist die gleichfalls in der basolateralen Membran gelegene $\mathrm{Na}^{+} / \mathrm{K}^{+}$-ATPase (aus Gründen der Übersichtlichkeit nicht eingezeichnet), welche durch den Austausch von 3 intrazellulären Natrium-lonen für 2 extrazelluläre Kalium-Ionen Energie bereitstellt. Die in der luminalen Membran situierten Transporter OAT4 etc. (dargestellt durch ein ?, da sie noch nicht alle bekannt sind) dienen der Abgabe organischer Anionen in das Tubuluslumen.

\subsection{2 $\mathrm{Na}^{+}$-abhängige Dikarboxylat-Cotransporter (NaDCs)}

Die in der proximalen Tubuluszelle gelegenen $\mathrm{Na}^{+}$-abhängigen DikarboxylatCotransporter gehören zur SLC13 Gen-Familie. Sie werden als niedrig-affiner $\mathrm{Na}^{+}-$ abhängiger Dikarboxylat-Cotransporter (oder auch NaDC1 bzw. SLC13A1) und als hoch-affiner $\mathrm{Na}^{+}$-abhängiger Dikarboxylat-Cotransporter (oder NaDC-3 bzw. SLC13A3) bezeichnet (MARKOVICH und MURER 2004).

Proteine deren funktionelle Charakteristik dem niedrig-affinen $\mathrm{Na}^{+}$-abhängigen Dikarboxylat-Cotransporter zugeordnet werden kann, konnten bis jetzt vom Kaninchen, von der Ratte und der menschlichen Niere kloniert werden (Übersicht in: MARKOVICH und MURER 2004, PAJOR 2006). Für den hoch-affinen NaDC-3 
gelang es, die kodierende cRNS von der Plazenta der Ratte (KEKUDA et al 1999), aus dem Mäusegehirn (PAJOR et al. 2001) und von der menschlichen Niere bzw. der Rattenniere zu klonieren (WANG H et al 2000, CHEN et al 1999). Außer in der Membran des proximalen Tubulus konnte durch Northern blots der humane Typ des NaDC-1 noch im Intestinaltrakt (PAJOR und SUN 1996) und der humane Typ des NaDC-3 außerdem im Gehirn, in der Leber, im Pankreas und in der Plazenta nachgewiesen werden (WANG H et al. 2000).

Beide Transporter unterschieden sich außer in ihrer Substrataffinität, durch ihre Lokalisation, ihre Funktion, sowie in der pH-Abhängigkeit des Substrattransportes (PAJOR 1999). Der NaDC-1 ist in der luminalen Bürstensaummembran der proximalen Tubuluszelle lokalisiert. Seine Hauptaufgabe besteht darin, die glomerulär frei filtrierbaren Citratcyclus-Derivate aus dem tubulären Lumen in die Zelle zurückzutransportieren. In der Tubuluszelle werden diese Substrate entweder in den zelleigenen Mitochondrien metabolisiert oder für den Austausch von organischen Anionen benötigt (PAJOR 1999).

Der NaDC-3 befindet sich dagegen in der basolateralen Membran der proximalen Tubuluszelle (WANG $\mathrm{H}$ et al. 2000) und dient dort zusammen mit dem NaDC-1, wie bereits erwähnt, zur Bereitstellung von ca. $60 \%$ des von den ebenfalls in der basolateralen Membran lokalisierten OAT1 und OAT3 benötigten $\alpha$-Ketoglutarat. Der restliche intrazelluläre Bedarf an $\alpha$-Ketoglutarat wird über im Zellstoffwechsel entstehendes $\alpha-K^{2-}$ abgedeckt (WANG $\mathrm{H}$ et al. 2000, BURCKHARDT BC et al. 2002, DANTZLER 2002; MARKOVICH und MURER 2004). Neben $\alpha$-Ketoglutarat besitzt der NaDC-3 eine besonders hohe Affinität zu Substraten mit einer Kohlenstoffkettenlänge von 4 bzw. 5 Kohlenstoffatomen, wie z.B. Succinat, Dimethylsuccinat, Meso-2-3-Dimercaptosuccinat, Fumarat (WANG H et al. 2000) oder 2,3-Dimercaptosuccinat, Glutarat, Glutaratderivate und Benzylpenicillin (BURCKHARDT BC et al. 2002, BURCKHARDT BC et al. 2004, BURCKHARDT BC et al. 2005, STELLMER et al. 2007, MÜHLHAUSEN et al. 2008, HAGOS et al. 2008). Beide Co-Transporter interagieren mit Citrat und spielen damit eine wichtige Rolle bei der Regulation des Citrathaushaltes durch die Niere. Citrat ist zum einen ein wichtiger Energielieferant für das Gewebe (NIETH und SCHOLLMEYER 1966) und verhindert zum anderen die Bildung von Kalziumsteinen in der Niere (ZUCKERMAN 
et al. 2009). Eine Fehlfunktion der NaDCs scheint eine entscheidene Rolle bei der Hypocitraturie-assozierten Nephrolithiasis zu spielen (OKAMOTO et al.2007)

\subsection{Zielsetzung}

Ziel unserer Untersuchungen war die Frage, ob der in der basolateralen Membran gelegene $\mathrm{Na}^{+}$-abhängige Dikarboxylat-Transporter ( $\mathrm{NaDC}-3$ ), neben seiner Funktion der Versorgung der proximalen Tubuluzelle mit $\alpha$-Ketoglutarat, eine Rolle in der Aufnahme von Diuretika über die basolaterale Membran ins Nierenzellinnere spielen könnte. Einen Hinweis darauf ließ sich in einer Studie finden, die 1989 von ULLRICH durchgeführt wurde (ULLRICH et al. 1989). In dieser wurde die Hemmung der $\left[{ }^{14} \mathrm{C}\right]$ Succinat-Aufnahme über die basolaterale Membran der Rattenniere insitu in Anwesenheit des Schleifendiuretikums Furosemid beschrieben $\left(K_{i}=5,1 \mathrm{mM}\right)$. ULLRICH erklärte die Hemmung des Furosemid auf die Aufnahme von $\left[{ }^{14} \mathrm{C}\right]$ Succinat über die basolaterale Membran der Rattenniere in-situ durch eine Konkurrenz des divalenten Succinats mit dem, aufgrund der Carboxyl- und Cl- Gruppen negativ geladenen Furosemid, an einer gemeinsamen Bindungsstelle am noch unbekannten Transportprotein.

Zur Beantwortung der Frage, wie Furosemid mit dem mittlerweile klonierten Transporter für Dikarboxylate, dem NaDC-3, interagiert, führten wir an Xenopuslaevis-Oozyten, die den humanen NaDC-3 (hNaDC-3) exprimiert hatten, Versuche mit $\left[{ }^{14} \mathrm{C}\right]$ Succinat und mit der Zwei-Elektroden-Spannungsklemm-Technik durch. Beide Versuchstechniken werden eingehend im folgenden Kapitel "Material und Methoden" beschrieben. In beiden Ansätzen sollte ein Einfluss des Furosemid auf die Translokation von Succinat über den $\mathrm{hNaDC}-3$ untersucht werden.

Bei der Aufnahme-Technik müsste es zu einer verringerten Aufnahme von Succinat in Anwesenheit von Furosemid kommen. Bei der Methode mittels Zwei-ElektrodenSpannungsklemm-Technik sollte der durch Succinat zu induzierende Strom, bei einer gleichzeitigen Gabe von Furosemid, ebenfalls signifikant gesenkt sein. Daran anschließend sollten Untersuchungen mit der gleichen Methode zeigen, ob Furosemid nur eine hemmende Wirkung auf den Transport von Succinat über den hNaDC-3 hat, oder ob es auch selber über den hNaDC-3 transportiert wird. 
Um die durch WANG H et al. 2000 gezeigte Natrium-Abhängigkeit des Transportes von Succinat über den $\mathrm{hNaDC}-3$ auch für den Furosemidtransport zu zeigen, wurden zudem Versuche durchgeführt, bei denen in der Oozyten-Ringer-Lösung Natrium durch $\mathrm{N}$-methyl-D-Glutamin ersetzt wurde. Bei einer Natrium-Abhängigkeit eines Transportes von Furosemid über den hNaDC-3 dürfte es so zu keinem induzierbaren Strom mehr kommen.

Zum Abschluss der Untersuchungen der Interaktion von Furosemid mit dem hNaDC3 sollte ein möglicher Einfluss von Lithium auf einen Furosemid-sensitiven Strom untersucht werden. Lithium ist ein Medikament welches vorwiegend zur Behandlung von psychischen Erkrankungen, wie bipolaren Störungen, Manien oder Depressionen eingesetzt wird (FÜLGRAFF und PALM 2001, BAUER et. al. 2004). Bei der Behandlung von Patienten mit Lithium fiel ein Anstieg der renalen Ausscheidung von Metaboliten des Citratzyklus auf (PAJOR 1999). Damit lag die Vermutung nahe, dass es durch eine Interaktion des Lithiums sowohl mit dem luminalen hNaDC-1 als auch mit dem basolateral lokalisierten hNaDC-3 zu einer Beeinflussung der Ausscheidung von Substanzen der hNaDCs kommen könnte. Bisherige Untersuchungen zeigten bereits eine Interaktion des Lithiums sowohl mit dem NaDC-1 als auch mit dem NaDC-3. Allerdings ergaben sich hierbei zum einen große Unterschiede zwischen den verschiedenen Spezies und zum anderen lagen beim humanen NaDC-3 die benötigten Lithium-Konzentration ab denen es zu einer Beeinflussung kam über der therapeutischen Dosis von 0,8-2,0 mM (PAJOR et al. 1998, WANG et. al. 2000, BURCKHARD BC et al. 2004, SPROULE 2002).

Untersuchungen über eine Wechselwirkung von Lithium und Diuretika im Rahmen eines Transportes über den hNaDC-3 wurden bisher noch nicht durchgeführt. Da sowohl Diuretika als auch Lithium therapeutisch häufig verwendete Medikamente sind, wäre ein möglicher wechselseitiger Einfluss durch den Transport über den hNaDC-3 von großem klinischem Interesse.

Ergänzend zu den Untersuchungen der Interaktion von Furosemid mit dem hNaDC-3 folgten einige Versuche mit der Furosemid-verwandten Substanz Bumetanid bzw. dem Schleifendiuretikum Etacrynsäure. Bumetanid ist ein dem Furosemid strukturverwandtes, neueres Schleifendiuretikum, welches bei gleicher Wirkung weniger Nebenwirkungen und höhere Resorptionsraten aufweist. 
Etacrynsäure gleicht hinsichtlich seiner Wirkungsweise, Indikation und Nebenwirkung den Schleifendiuretika. Es wird meist in Kombination mit Furosemid gegeben, da dadurch die diuretische Wirkung, insbesondere bei schwerer Herzinsuffizienz, gesteigert werden kann. Offensichtlich kann dadurch die Natriumresorption in weiten Abschnitten des Nephrons blockiert werden.

Hierzu wurden erneut Versuche mit der Zwei-Elektroden-Spannungsklemm-Technik an hNaDC-3 exprimierenden Oozyten durchgeführt. Dabei sollten zumindest die Messungen mit Bumetanid zu ähnlichen Ergebnissen wie Furosemid führen.

Als letztes sollten die Diuretika Azetazolamid und Sulfanilamid, Prototyp aller Sulfonamide, mittels der Zwei-Elektroden-Spannungsklemm-Technik auf ihre Interaktion mit dem hNaDC-3 getestet werden. Diese Diuretika gehören nicht zur Gruppe der Schleifendiuretika, sondern wirken über die Hemmung des Enzyms Carboanhydrase. Acetazolamid zeichnet sich ebenfalls neben der glomerulären Filtration durch tubuläre Sekretion aus und gehört zur Gruppe der Sulfonamide (TAFT und SWEENEY 1995, TAFT et al. 1996). Seine Anwendung liegt heutzutage hauptsächlich in der Glaukombehandlung. Acetazolamid verfügt aber auch über einen ausgeprägten diuretischen Effekt (YANO et al. 1998). 


\begin{tabular}{|l|l|}
\hline Fragestellung & Methode \\
\hline $\begin{array}{l}\text { 1. Hemmt Furosemid den Succinatransport über } \\
\text { den hNaDC-3? }\end{array}$ & $\begin{array}{l}\text { a) Aufnahmeversuche mit radioaktiv } \\
\text { markiertem Substrat } \\
\text { b) Voltage-Clamp-Methode }\end{array}$ \\
\hline $\begin{array}{l}\text { 2. Wird Furosemid über den hNaDC-3 } \\
\text { transportiert? }\end{array}$ & a) Voltage-Clamp-Methode \\
\hline $\begin{array}{l}\text { 3. Ist der Transport von Furosemid über den } \\
\text { hNaDC-3 Natrium-abhängig ? }\end{array}$ & a) Voltage-Clamp-Methode \\
\hline $\begin{array}{l}\text { 4. Wird der Transport von Furosemid über den } \\
\text { hNaDC-3 durch Lithium gehemmt ? }\end{array}$ & a) Voltage-Clamp-Methode \\
\hline $\begin{array}{l}\text { 5. Wird Bumetanid ebenfalls über den hNaDC-3 } \\
\text { transportiert? }\end{array}$ & a) Voltage-Clamp-Methode \\
\hline $\begin{array}{l}\text { 6. Überprüfung weiterer Diuretika auf den } \\
\text { Transport über den hNaDC-3 (Etacrynsäure, } \\
\text { Azetazolamid, Sulfanilamid) }\end{array}$ & a) Voltage-Clamp-Methode \\
\hline
\end{tabular}

Tabelle 2: Zusammenfassung der Forschungsziele 


\section{Material und Methoden}

\subsection{Entnahme und Präparation der Oozyten}

\subsubsection{Oozyten des Xenopus laevis}

Die Untersuchungen wurden mit Oozyten des südafrikanischen Krallenfrosches Xenopus laevis durchgeführt. Diese stammen von der Firma Nasco aus Fort Atkinson in Wisconsin (USA).

Die Oozyten dieser Spezies eignen sich ausgezeichnet als Expressionssystem für Membranproteine, da sie auf Grund ihrer Omnipotenz und Undifferenziertheit die Fähigkeit besitzen, zytosolisch injizierte heterologe RNS effizient zu translatieren (DAWID und SARGENT 1988). Außerdem gestattet die Größe der Oozyten (durchschnittlicher Durchmesser 1,1-1,3 mm), sowie die Reserve einer großen Menge an Enzymen, Proteinen und Organellen für die embryonale Entwicklung, die auch der Expression einer exogenen mRNS zugute kommt, eine gute Handhabung. (WAGNER et al. 2000).

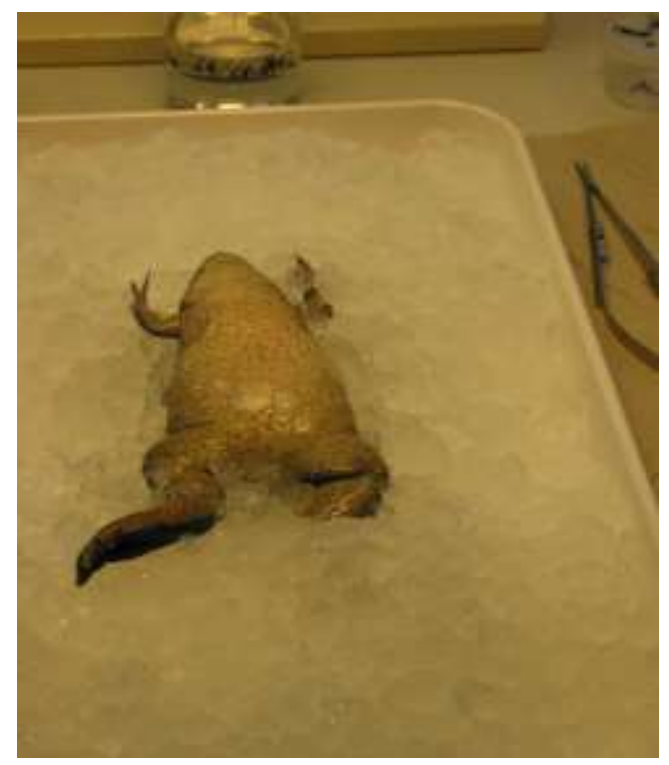

Abbildung 5: Darstellung des Krallenfrosches Xenopus laevis vor der Oozytenentnahme im Eisbad 
Die Oogenese der Oozyten lässt sich in 6 Stadien einteilen. Diese verlaufen zwar kontinuierlich, aber asynchron, wodurch gleichzeitig alle Stadien in den Ovarien vorkommen (DUMONT 1972). Für die Expressionsversuche können nur Oozyten im Stadium V und VI verwendet werden, da nur diese Stadien die notwendige Reife aufweisen. Diese beiden Stadien machen ca. 25\% aller Oozyten in den Ovarien des Xenopus - laevis aus. Oozyten im Endstadium VI erreichen einen Durchmesser von bis zu 1,3 mm und bestehen aus zwei Hemisphären, die durch ein Äquatorialband getrennt werden.

\subsubsection{Entnahme der Oozyten}

Die Entnahme der Oozyten erfolgt ca. 2 - 4 Tage vor der elektrophysiologischen Untersuchung aus einem Xenopus - laevis - Weibchen. Für die Entnahme wird das Tier mittels Hypothermie für 40 - 45 Minuten in einem Eiswasserbad, dem 3Aminobenzoesäure-Ethylester (Tricain 0,2\%) zugesetzt wird, anästhesiert. Um an das ovarielle Gewebe zu gelangen, wird ein kleiner $(<1 \mathrm{~cm})$ abdomineller Schnitt an der posterior-ventralen Seite des Tieres durchgeführt. Nach Entnahme einzelner Ovarläppchen wird das eröffnete Abdomen durch je eine separate Muskel- und Hautnaht verschlossen. Der Wundverlauf ist komplikationslos, so dass das Froschweibchen schon nach einigen Monaten zur erneuten Entnahme von Oozyten genutzt werden kann.

Die entnommenen Ovarläppchen werden sofort nach Entnahme in eine OozytenRinger Lösung (ORi, Konzentration in mM: $110 \mathrm{NaCl}, 3 \mathrm{KCl}, 2 \mathrm{CaCl}_{2} \mathrm{HEPES} / \mathrm{Tris}, \mathrm{pH}$ 7.5, HEPES: N-(2-Hydroxyethyl)-piperazin-N'(2-Äthansulfonsäure)) gelegt. 


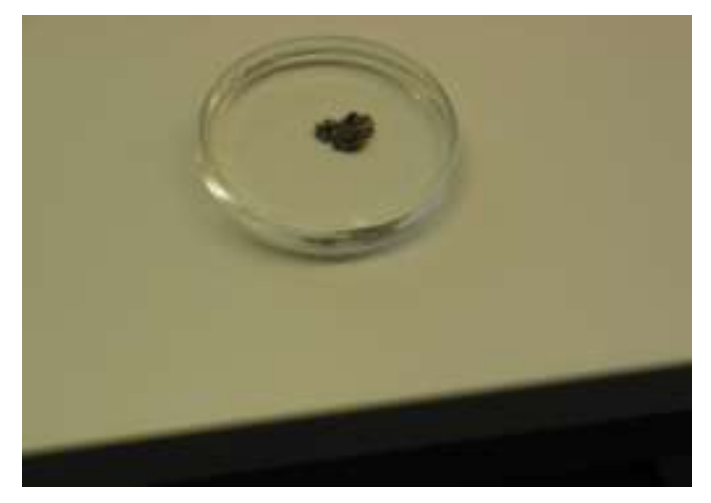

Abbildung 6: Darstellung der operativ entnommenen Ovarialläppchen von Xenopus laevis.

Um die Oozyten von dem sie umgebenden Bindegewebe zu befreien, wird innen das Enzym Kollagenase (Typ CLS 2, Biochrom, Berlin, Deutschland) in einer Konzentration von $7 \mu \mathrm{g} / 20 \mathrm{ml}$ in ORi zugesetzt. Die Oozyten werden in dieser Lösung für ca.16 Stunden bei $16-18^{\circ} \mathrm{C}$ in einem Inkubator gehalten. Anschließend werden die Oozyten in $\mathrm{Ca}^{2+}$-freiem ORi für zehn Minuten inkubiert, um letzte bindegewebige Strukturen aufzulösen. Die nun einzeln vorliegenden Oozyten werden durch mehrmaliges Waschen in ORi von Follikelresten und Bindegewebe befreit. Anschließend werden diejenigen Oozyten, die sich nicht im Reifestadium V oder VI befinden, aussortiert und verworfen. Bis zur Mikroinjektion werden die übrig gebliebenen Oozyten bei $16-18^{\circ} \mathrm{C}$ in einem Inkubator in ORi gehalten.

Die oben beschriebenen Vorgänge wurden nicht von mir persönlich, sondern von einer dafür speziell ausgebildeten Institutsmitarbeiterin durchgeführt. Der Eingriff zur Entnahme der Oozyten wird nach den geltenden Tierschutzvorschriften durchgeführt. Eine Ausnahmegenehmigung nach $\S 9$ Abs. 1 Satz 4 des Tierschutzgesetzes liegt vor.

\subsubsection{Injektion der Oozyten mit cRNA}

Einen Tag nach der Entnahme aus dem Froschweibchen werden den defollikulierten Oozyten mittels einer speziellen Injektionspumpe $30 \mathrm{nl}$ für den hNaDC-3 codierende cRNA (1 $\mu \mathrm{g} / \mu \mathrm{l})$ injiziert. Zur Kontrolle werden jedes Mal Oozyten mit $\mathrm{H}_{2} \mathrm{O}$ injiziert, um auszuschließen, dass die Oozyten auf Substratgabe durch endogene Transporter dem hNaDC-3 ähnliche Antworten hervorrufen. Anschließend müssen die Oozyten 3 -4 Tage bei $18^{\circ} \mathrm{C}$ inkubiert werden. Um bakterielle Kontaminationen zu vermeiden, 
werden Antibiotika dem Inkubationsmedium (ORi plus Penicillin (100 kU/l) und Streptomycin $(0,1 \mathrm{mg} / \mathrm{l}))$ zugesetzt. Die Inkubationslösung muss jeden Tag gewechselt werden, da abgestorbende oder verletzte Oozyten Salz verlieren und eventuell Substanzern freisetzen, welche die noch intakten Oozyten zerstören könnten.

Die so präparierten Oozyten können nun sowohl für die Zwei-ElektrodenSpannungsklemm-Technik als auch für die Aufnahme der radioaktiv markierten Substanzen benutzt werden.

\subsection{Die elektrophysiologische Messung}

\subsubsection{Messplatz}

Die Messapparatur setzt sich aus dem Stereomikroskop, den Elektrodenhaltern, den Mikromanipulatoren und dem Perfusionsystem, sowie dem Verstärker und dem Flachbettschreiber zur Aufzeichnung der Signale zusammen. Aufgebaut ist das Ganze auf einer schwingungsfrei gelagerten Arbeitsplatte und wird von einem nach vorne offenen Faraday-Käfig umgeben.

Das Perfusionsystem besteht aus verschiedenen Anteilen: Die ca. $70 \mathrm{~cm}$ oberhalb der Perfusionskammer angebrachten Vorratsbehälter für die Kontroll- und Testlösungen sind mittels Polyäthylenschläuche mit der Perfusionskammer verbunden. Die Perfusionskammer besteht aus einer runden Kunststoffplatte (Dicke $1 \mathrm{~cm}$, Durchmesser $6 \mathrm{~cm}$ ) mit zentraler Vertiefung (Breite $0,5 \mathrm{~cm}$, Tiefe $0,3 \mathrm{~cm}$ ), die durch einen Kunststoffsteg in eine rechte und linke Kammer unterteilt wird. In den rechten Teil münden die beiden Polyäthylenschläuche. Der Abfluss der in die Perfusionskammer gelangten Kontroll- und Testlösungen geschieht durch ein Loch in der linken Kammer, welches durch einen Trichter mit einem Auffangbehälter verbunden ist. So entsteht ein kontinuierlich perfundiertes offenes System mit einer Durchflussrate von ca. $4 \mathrm{ml} / \mathrm{min}$. 


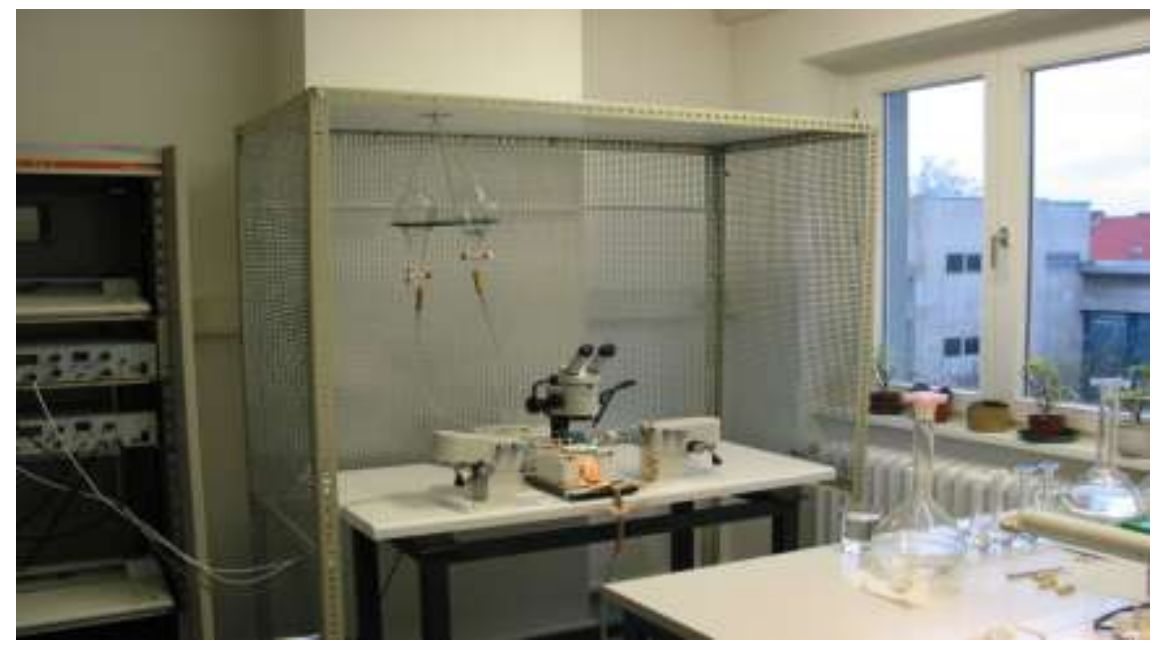

Abb.7: Übersichtsaufnahme der gesamten Messapparatur. Die Perfusionskammer mit Stereomikroskop und Elektrodenmikromanipulatoren befindet sich im Zentrum der schwingungsfrei gelagerten Tischplatte. Im Faradayschen Käfig erkennt man die Testlösungsbehälter mit Schlauchsystem. Links befindet sich der Zweikanalschreiber sowie der Voltage-Clamp-Verstärker. In der Abbildung rechts unten erkennt man die unterschiedlichen Aufbewahrungsgefäße mit den Testlösungen.

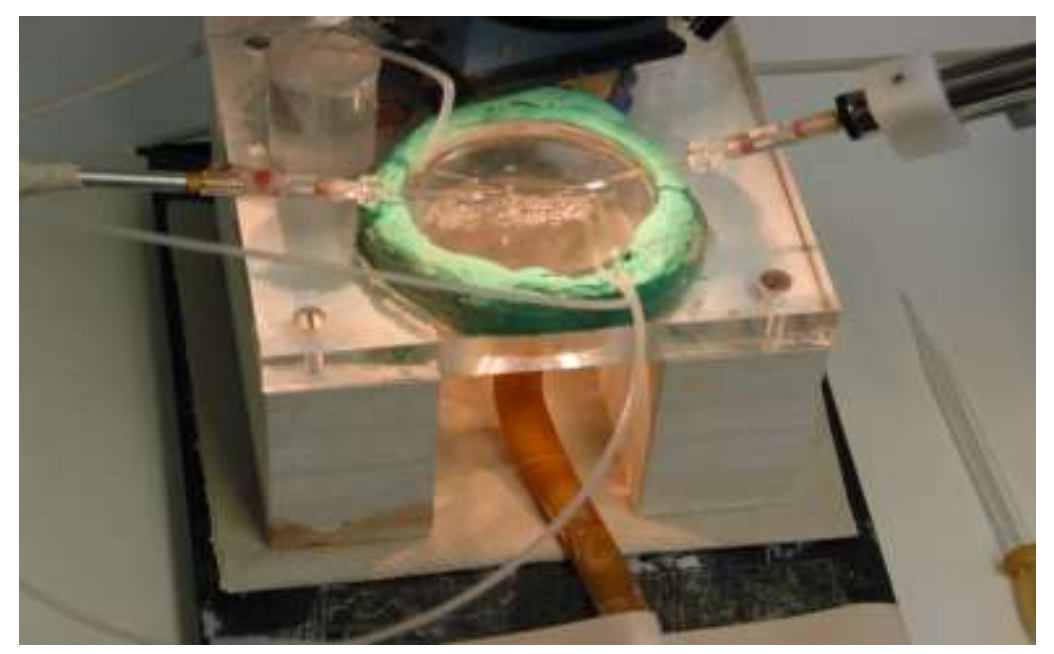

Abb.8: Darstellung der Perfusionskammer am Messplatz. Links ist die stromeinspeisende Elektrode zu erkennen und auf der rechten Seite die spannungsmessende Elektrode. Die Perfusionskammer, in der die Oozyte während der Experimente platziert wird, befindet sich im Zentrum des Ganzen. Im unteren Teil der Abbildung sieht man die zu- und abführenden Schlauchsysteme, links oberhalb der Perfusionskammer ist eine Agarbrücke erkennbar. 


\subsubsection{Registrierung der Messwerte}

Die Registrierung der Messwerte erfolgt über einen angeschlossen Flachbettschreiber. Dieser hält die sich aus den vorgegebenen Potenzialkennlinien ergebenden Stromverläufe fest. Die Aufzeichnung verläuft mit einer Geschwindigkeit von $0,1 \mathrm{~mm} / \mathrm{min}$. bis $20 \mathrm{~mm} / \mathrm{sec}$.

\subsubsection{Vorbereitung der Mikroelektroden}

Diese speziellen Glasmikroelektroden werden aus Borosilikatglaskapillaren (Außendurchmesser $1 \mathrm{~mm}$, Innendurchmesser 0,85 mm mit Filament) gefertigt. Die Glaskapillaren werden in einem elektromagnetischen Vertikalpuller an beiden Enden eingespannt und anschließend von der sie mittig umgebenden Heizspirale und der vertikalen Zugkraft an beiden Enden in zwei Teile getrennt. Dadurch entstehen konisch zulaufende Glaskapillaren. Vor der Messung wird ca. das erste Drittel der Glaskapillaren mittels einer Spritze (dünne flexible Kanüle) mit einer 3-molaren $\mathrm{KCl}$ Lösung aufgefüllt und eventuell beim Füllen entstandene Luftblasen durch leichtes Klopfen entfernt. Die so präparierten Glaskapillaren werden nun auf die aus chloriertem Silberdraht bestehenden Elektroden des Mikromanipulators gesetzt. Die Glaskapillaren dienen so als Verlängerung für die Silberdrähte, die auf Grund von die Oozyte beeinflussenden elektromechanischen und elektrochemischen Prozessen, nicht direkt als Elektrode verwendet werden können

\subsubsection{Messung mit der Zwei-Elektroden-Spannungsklemm-Technik}

Ursprünglich wurde die Spannungsklemm-Technik von Hodgkin, Huxley und Katz (HODGKIN et al. 1952) entwickelt, um elektrisch erregbare Zellmembranen zu erforschen. Dabei wurde das Membranpotenzial eines Tintenfischaxons künstlich auf einem konstanten Wert gehalten und der daraus resultierende Membranstrom gemessen. Das Membranpotenzial $\left(\mathrm{V}_{\mathrm{m}}\right)$ resultiert aus der unterschiedlichen Konzentration von lonen im intrazellulären und im extrazellulären Raum, sowie der selektiven Durchlässigkeit der Membran für die lonenarten. Das Messprinzip beruht darauf, dass das Membranpotenzial $\left(V_{m}\right)$ mit Hilfe einer Mikroelektrode gemessen 
und mit der gewünschten Kommandospannung $\left(\mathrm{V}_{\mathrm{c}}\right)$ verglichen wird.

Bei der Zwei-Elektroden-Spannungsklemm-Technik werden zwei Glaspipettenelektroden in die in einer Kammer mit Pufferlösung liegende Oozyte eingestochen (Abb.9). Über die spannungsmessende Elektrode wird das Potenzial, das über der Oozytenmembran anliegt, gemessen. Über die stromeinspeisende Elektrode wird der kompensatorische Strom $\mathrm{I}_{\mathrm{m}}$ in die Zelle appliziert. Als Referenzelektrode dient eine Badelektrode. Mittels eines Voltage-Clamp Verstärkers kann das Membranpotenzial $\left(\mathrm{V}_{\mathrm{m}}\right)$ konstant gehalten werden. Dafür wird das Membranpotenzial der Zelle am Verstärker gemessen und anschließend mit der Kommandospannung $\left(\mathrm{V}_{\mathrm{c}}\right)$ am Differenzverstärker verglichen. Durch die Applikation eines Stromes I lassen sich die Unterschiede zwischen dem gemessenen Membranpotenzial $\left(\mathrm{V}_{\mathrm{m}}\right)$ und der vorgegebenen Kommandospannung $\left(\mathrm{V}_{\mathrm{c}}\right)$ kompensieren. Dabei ist der zur Konstanthaltung der Kommandospannung notwendige Strom genauso groß wie der lonenstrom, der durch die Membran fließt. Über einen Strom/Spannungswandler wird der kompensatorische Strom $I_{m}$ in die Zelle appliziert. Auf diese Weise erhält man für jede Spannung einen resultierenden Strom, der von einem Zweikanalschreiber als so genannte Strom-SpannungsKennlinie (I-V-Kennlinie) kontinuierlich aufgezeichnet wird.

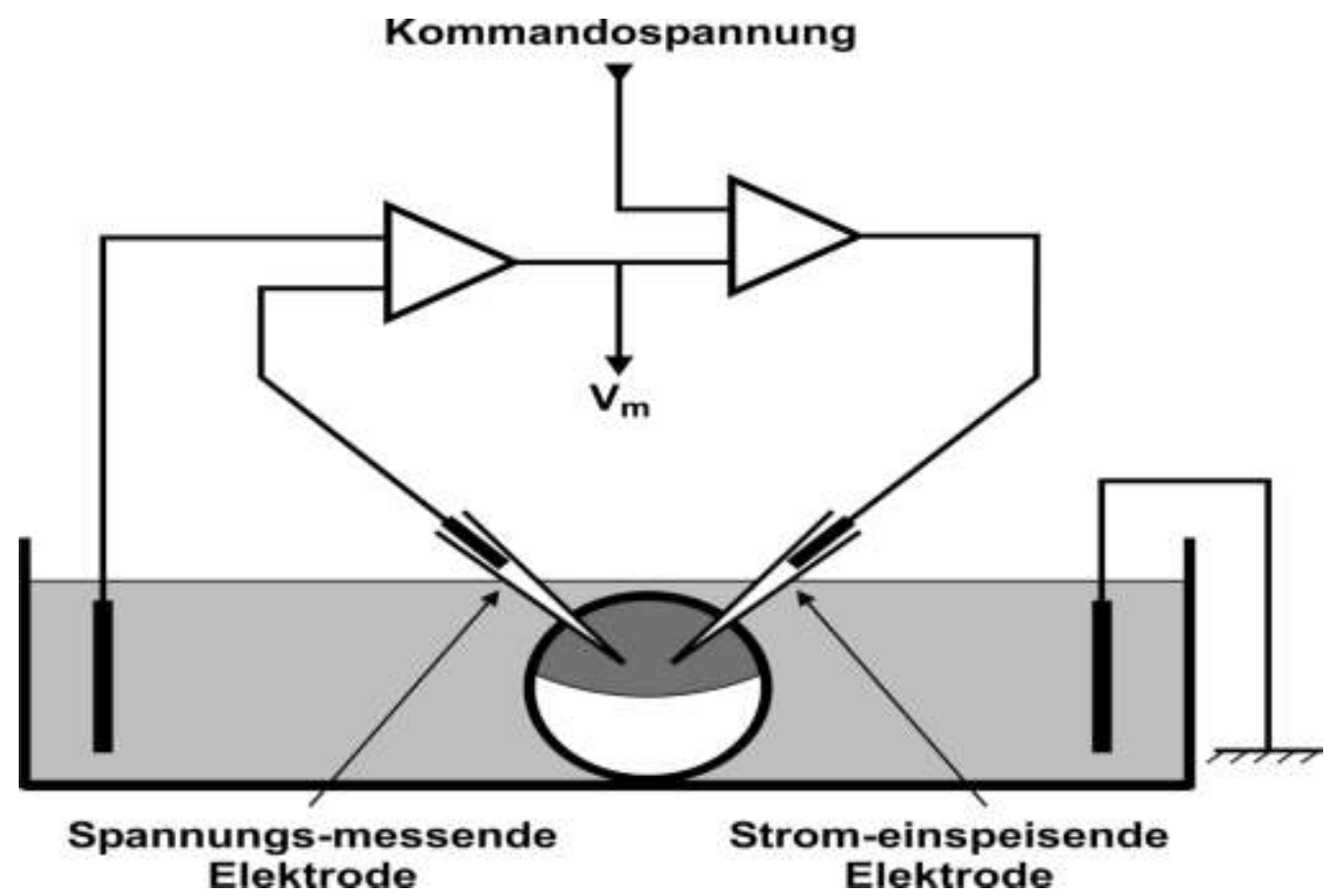

Abb.9: Vereinfachter Schaltplan der Zwei-Elektroden-Spannungsklemm-Technik 
Nach Aufbau der oben beschrieben Messapparatur wird die Oozyte, nach Entnahme aus dem Inkubatur, in den linken Teil der Perfusionskammer mittels einer Pasteurpipette platziert. Dort erfolgt unter mikroskopischer Kontrolle das Einstechen der linken spannungsmessenden Elektrode in die Oozyte unter einem Winkel von ca. $45^{\circ}$ zur Perfusionskammer. Anschließend wird die Oozyte über den Steg gehoben und auf der rechten Seite wieder abgesetzt. Nun kann die rechte stromeinspeisende Elektrode ebenfalls unter mikroskopischer Kontrolle platziert werden. Um den Stromkreis zu schließen, müssen des Weiteren zwei aus chloriertem Silberdraht bestehende Badelektroden, die sich in einem Behältnis mit gesättigter $\mathrm{KCl}$-Lösung befinden, durch eine Agarbrücke mit der Perfusionskammer in Verbindung gebracht werden. Die Oozyte wird anfänglich so lange mit einem Oozyten-Ringer (ORi, siehe Teil „Lösungen und Chemikalien) umspült, bis sich ein stabiles Membranpotenzial eingestellt hat. Im Normalfall dauert dies ungefähr 10-15 Minuten. Bei korrekter Lage der Elektroden sollte das von der Spannungselektrode gemessene Membranpotenzial der Oozyte zwischen -20 mV und $-50 \mathrm{mV}$ liegen. Da das Zellmembranpotenzial der proximalen Tubuluszelle in situ ungefähr bei $-60 \mathrm{mV}$ liegt, wird die Oozyte zunächst auf ein entsprechendes Potenzial geklemmt. Der nun gemessene Strom entspricht dem Strom, der notwendig ist, die Oozyte auf dem vorgegebenen Potenzial zu halten (Haltestrom).

Begonnen wird die Messung zunächst mit ORi in Abwesenheit des Substrats, dann mind. 30 Sekunden abgewartet und anschließend werden in 10-mV-Schritten Ergebnisse unter Perfusion mit einer Testlösung (wie z.B. mit durch $1 \mathrm{mM}$ Succinat angereichertem ORi) erhoben. Die Differenz der "steady-state“-Ströme in An- und Abwesenheit des Substrates ergibt dann den Substrat-induzierten Strom.

Werden an einer Oozyte mehrere Substrate bzw. Substratkonzentrationen untersucht, muss zwischen den einzelnen Messungen eine Pause von 15-20 Minuten eingelegt werden, damit sich die Oozyte wieder stabilisieren kann. Der Haltestrom bei $-60 \mathrm{mV}$ sollte dann in etwa den Ausgangswert wie zu Anfang der Messungen besitzen. Unter den gleichen Bedingungen werden die Versuche an $\mathrm{H}_{2} \mathrm{O}-$ injizierten Kontrolloozyten durchgeführt. 


\subsection{Transportmessungen mit radioaktiv-markiertem Substrat}

Hierbei werden jeweils 5-10 hNaDC-3 bzw. Wasser-injizierte Oozyten für 30 Minuten in einer ORi mit entsprechend zugefügtem zu untersuchendem radiomarkiertem Substrat inkubiert. Die Oozyten sind zuvor wie für die Untersuchungen mit der ZweiElektroden-Voltage-Clamp-Technik (siehe 2.1) präpariert worden. Zum Ende der Inkubationszeit wird zum Stoppen der temperaturabhängigen Aufnahme 1-1,5 ml eiskalter ORi-Puffer in das Inkubationsgefäß pipettiert und das Inkubationsmedium aspiriert. Anschließend werden die Oozyten entnommen und dreimal in eiskaltem ORI gewaschen, um extrazellulär vorhandenes radioaktiv-markiertes Material zu entfernen. Die Oozyten werden dann einzeln in die Szintillationsgefäße pipettiert. Nun erfolgt die Lysierung der Oozyten durch Schwenken der gefülten Szintillatoinsgefäße für 120 Minuten auf einem Exzenter-Schüttler unter Zugabe von $100 \mu \mathrm{l} 1 \mathrm{~N} \mathrm{NaOH}$. Anschließend werden die Proben durch Zugabe von $100 \mu \mathrm{l}$ einer 1 molaren HCl-Lösung neutralisiert. Nach der Lyse der Oozyten wird jedes Szintillationsgefäß mit 2,5 ml Szintillationscocktail angereichert, verschlossen und in einem Flüssigkeitszintillationszähler analysiert. Anhand der gemessenen $\beta$-Strahlung in Zerfälle pro Minute (decays per minute (dpm)) kann auf die Menge des aufgenommenen radioaktiv markierten Substrates geschlossen werden.

\subsection{Lösungen und Chemikalien}

\subsubsection{Zusammensetzung der Kontrolllösung ORi}

$\begin{array}{ll}90 \mathrm{mM} \mathrm{NaCl} & =5,260 \mathrm{~g} / \mathrm{l} \\ 3 \mathrm{mM} \mathrm{KCl} & =0,224 \mathrm{~g} / \mathrm{l} \\ 2 \mathrm{mM} \mathrm{CaCl}_{2} & =0,294 \mathrm{~g} / \mathrm{l} \\ 1 \mathrm{mM} \mathrm{MgCl}_{2} & =0,203 \mathrm{~g} / \mathrm{l} \\ 5 \mathrm{mM} \mathrm{HEPES} & =1,193 \mathrm{~g} / \mathrm{l}\end{array}$

Der $\mathrm{pH}$-Wert der Lösung wird anschließend durch Tris auf 7,5 bei Zimmertemperatur titriert. In ORi werden alle zu testenden Substanzen gelöst. Nur bei den Versuchen unter natriumfreien Bedingungen wurde Natrium durch $\mathrm{N}$-methyl-D-Glutamin (NMDG) ersetzt und mit $\mathrm{HCl}$ auf pH 7.5 titriert, um das entsprechende Chloridsalz zu erhalten. 


\subsubsection{Zusatzstoffe für die Aufbewahrungslösung der Oozyten}

Dem ORi wurden noch folgende Substanzen zugesetzt, um die Lebensdauer und das Expressionsverhalten der Oozyten zu verbessern.

100 kU// Penicillin

$0,1 \mathrm{mg} / \mathrm{l}$ Streptomycin

2,5 mM Natriumpyruvat

\subsubsection{Molekulargewichte der getesteten Substanzen}

$\begin{array}{lll}\text { Acetazolamid } & =222,2 \mathrm{~g} / \mathrm{mol} \\ \text { Bumetanid } & =364,4 \mathrm{~g} / \mathrm{mol} \\ \text { Etacrynsäure } & =303,2 \mathrm{~g} / \mathrm{mol} \\ \text { Furosemid } & =330,7 \mathrm{~g} / \mathrm{mol} \\ \text { Lithium } & =6,9 \mathrm{~g} / \mathrm{mol} \\ \text { Succinat (Natrium-Salz) } & =118,1 \mathrm{~g} / \mathrm{mol} \\ \text { Sulfanilamid } & =172,2 \mathrm{~g} / \mathrm{mol}\end{array}$

\subsubsection{Testsubstanzen}

0,5 mM Acetazolamid

0,5 mM Bumetanid

$0,5 \mathrm{mM}$ Etacrynsäure

0,1 mM Furosemid

0,25 mM Furosemid

0,5 mM Furosemid

1,0 mM Furosemid

2,0 mM Furosemid

5,0 mM Furosemid

2,0 mM Lithium

1,0 mM Succinat

$0,5 \mathrm{mM}$ Succinat

0,5 mM Sulfanilamid

$$
\begin{aligned}
& =0,111 \mathrm{~g} / \mathrm{l} \\
& =0,182 \mathrm{~g} / \mathrm{l} \\
& =0,152 \mathrm{~g} / \mathrm{l} \\
& =0,033 \mathrm{~g} / \mathrm{l} \\
& =0,083 \mathrm{~g} / \mathrm{l} \\
& =0,165 \mathrm{~g} / \mathrm{l} \\
& =0,331 \mathrm{~g} / 1 \\
& =0,661 \mathrm{~g} / 1 \\
& =1,654 \mathrm{~g} / \mathrm{l} \\
& =0,014 \mathrm{~g} / \mathrm{l} \\
& =0,118 \mathrm{~g} / \mathrm{l} \\
& =0,059 \mathrm{~g} / \mathrm{l} \\
& =0,086 \mathrm{~g} /
\end{aligned}
$$




\subsubsection{Herkunft der verwendeten Chemikalien}

\begin{tabular}{|l|l|}
\hline Substanz & Bezugsfirma \\
\hline Azetazolamid & Sigma, Taufkirchen \\
\hline Bumetanid & Sigma, Taufkirchen \\
\hline Calciumchlorid $\left(\mathrm{CaCl}_{2}\right)$ & Merck VWR International \\
\hline Furosemid & Sigma, Taufkirchen \\
\hline HEPES & Carl Roth, Karlsruhe \\
\hline Hydrochlorothiazid & Sigma, Taufkirchen \\
\hline Kaliumchlorid $(\mathrm{KCl})$ & Merck VWR International \\
\hline Lithium & Sigma, Taufkirchen \\
\hline Magesiumchlorid $\left(\mathrm{MgCl}_{2}\right)$ & Merck VWR International \\
\hline Natriumchlorid $(\mathrm{NaCl})$ & Merck VWR International \\
\hline Penicillin & Sigma, Taufkirchen \\
\hline Streptomycin & Sigma, Taufkirchen \\
\hline Succinat & Sigma, Taufkirchen \\
\hline$\left[{ }^{14} \mathrm{C}\right]$ Succinat & Amersham Pharmacia Biotech UK Limited \\
\hline Tris & Merck VWR International \\
\hline
\end{tabular}

Tabelle 3: Verwendete Chemikalien 


\subsection{Geräteliste}

\begin{tabular}{|c|c|c|}
\hline Gerätebezeichnung & Hersteller/Bezugsquelle & Modellbezeichnung \\
\hline Borosilikatglaskapillaren & BioMedical Instruments & \begin{tabular}{|l|} 
Durchmesser $=1,5 \mathrm{~mm}$ \\
Wandstärke $=0,86 \mathrm{~mm}$ \\
\end{tabular} \\
\hline Elektrodenhalter, Spannung & Warner Instrument Corp., USA & ESW-F15V, ESP F15V \\
\hline Elektrodenhalter, Strom & Warner Instrument Corp., USA & E45W \\
\hline Faraday-Käfig & Eigenbau:Werkstatt des Instituts & \\
\hline Flachbettschreiber & Kipp und Zonen Holland & 2-Kanal Modell BD 112 \\
\hline Glasgeräte & Schott & Duran \\
\hline $\begin{array}{l}\text { Glaskapillaren für die } \\
\text { Mikroinjektion }\end{array}$ & Hilgenberg & Sodarklarglas \\
\hline $\begin{array}{l}\text { Holzarbeitstisch mit Vestolit - } \\
\text { Puffer }\end{array}$ & Eigenbau: Werkstatt des Instituts & Vestolit-Leica \\
\hline Kaltlichtlampen & Schott, Deutschland & KL 1500 electronic \\
\hline Mikromanipulatoren & Zeiss, Deutschland & Modell M \\
\hline Nanoliterpumpe & $\begin{array}{l}\text { World Precision Instruments, } \\
\text { Sarasota, FL, USA }\end{array}$ & Nanoliter 2000 \\
\hline $\begin{array}{l}\text { Oozyteninkubator } \\
\text { (Kühlschrank) }\end{array}$ & $\begin{array}{l}\text { Liebherr (Umbau in der Werkstatt } \\
\left.\text { des Instituts auf } 18-20^{\circ} \mathrm{C}\right)\end{array}$ & \\
\hline Perfusionskammer & Eigenbau:Werkstatt des Instituts & \\
\hline Perfusionssystem & Eigenbau:Werkstatt des Instituts & \\
\hline Stereomikroskope & Wild/Zeiss & Serie M 3 \\
\hline Vertikalpuller & Narishige, Japan & Typ PE-2 \\
\hline Voltage-Clamp-Verstärker & Warner Instrument Corp., USA & $\begin{array}{l}\text { Model OC- } 725 \mathrm{~A} \\
\text { Oocyte clamp }\end{array}$ \\
\hline
\end{tabular}

Tabelle 4: Verwendete Arbeitsgeräte 


\section{Ergebnisteil}

\subsection{Interaktion von Succinat mit dem hNaDC-3}

Ziel der Arbeit war es, die Interaktionen verschiedener Diuretika mit dem Natriumabhängigen Dikarboxylat-Transporter des Menschen (hNaDC-3) zu untersuchen. Bevor mit den eigentlichen Experimenten begonnen werden konnte, musste zuerst sichergestellt sein, dass die Oozyten den hNaDC-3 auch exprimiert hatten. Dies geschah durch Perfusion der Oozyten mit Succinat, dem prototypischen Substrat des hNaDC-3. Abbildung 10 zeigt ein solches Experiment.

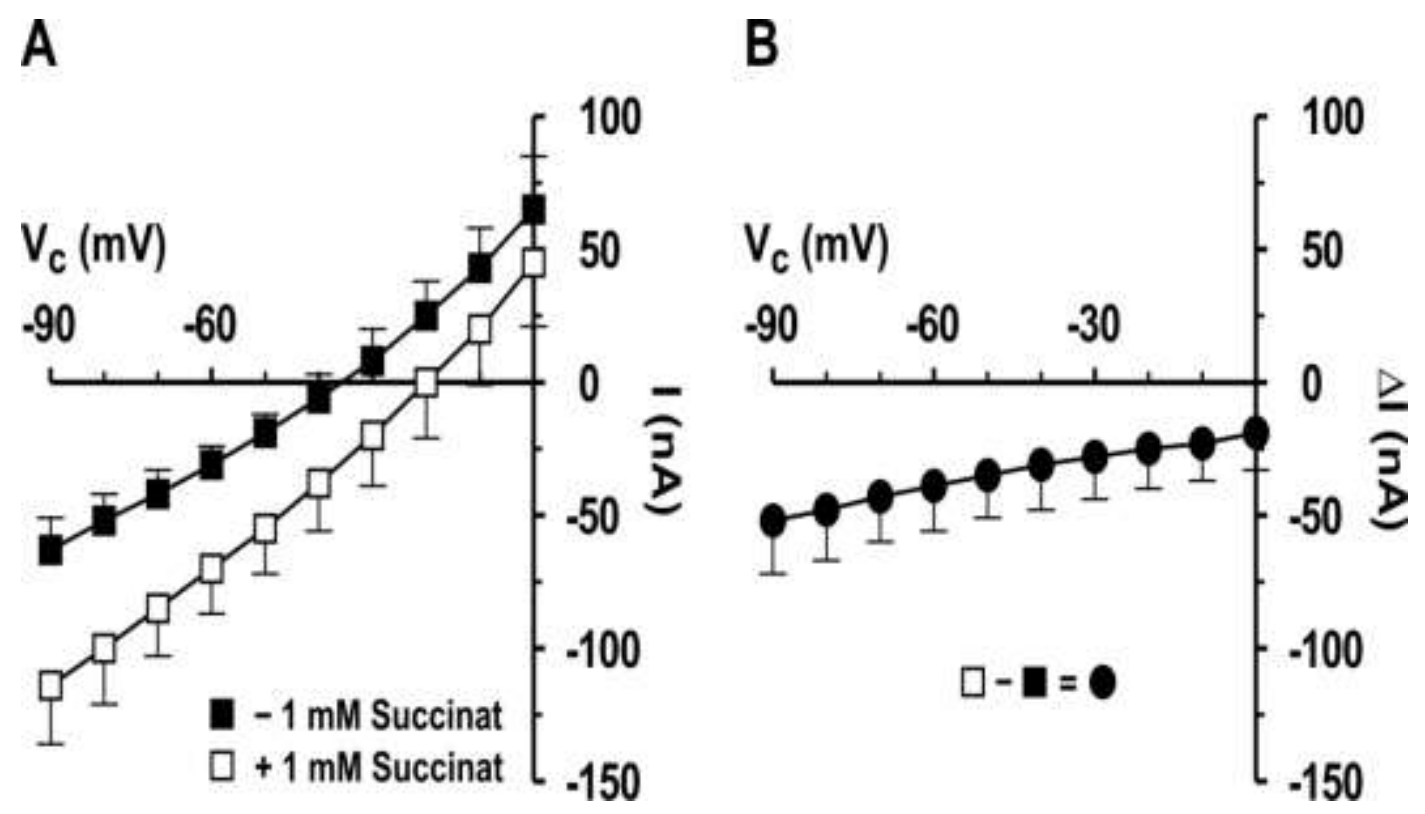

Abbildung 10: Charakterisierung der durch Succinat hervorgerufenen Ströme. A: StromSpannungskennlinien (I-V-Kennlinien) hNaDC-3-injizierter Oozyten unter Perfusion mit Oozyten-Ringerlösung (ORi) in Abwesenheit und in Anwesenheit von $1 \mathrm{mM}$ Succinat. Die Quadrate symbolisieren die einzelnen Messwerte, wobei die schwarzen Quadrate für ORi ohne Zusatz von $1 \mathrm{mM}$ Succinat und die weiß-gefüllten Quadrate für die ORi-Lösung unter Zugabe von $1 \mathrm{mM}$ Succinat stehen. Auf der Abszisse ist das Haltepotenzial $\left(V_{c}\right)$ in $\mathrm{mV}$ aufgetragen, auf der Ordinate die jeweils einzuspeisenden Ströme (I) in nA. Diese Form der Darstellung wurde auch in den weiteren Experimenten mit der Zwei-ElektrodenSpannungsklemm-Technik beibehalten. (B) Succinat-mediierte potenzialabhängige 
Differenzströme $(\Delta \mathrm{I})$. Die Abbildung stellt die an 10 Oozyten von 8 Spendertieren gemessenen Mittelwerte dar.

In Abbildung 10 sind die Strom-Spanungskennlinien (I-V-Kennlinien) im Bereich zwischen -90 mV und $0 \mathrm{mV}$ dargestellt, die sich durch Gabe der Oozyten-RingerLösung ORi in Abwesenheit und Anwesenheit von 1,0 mM Succinat ergeben. Die durch Succinat induzierte Differenzströme $\Delta \mathrm{I}$ (Abbildung 10B), ergeben sich aus der Differenz zwischen den in Abbildung 10A dargestellten Strömen in Ab- und Anwesenheit von 1,0 mM Succinat. Diese, durch Succinat hervorgerufene Ströme, sind potenzialabhängig und betragen bei einem Klemmpotenzial von $-90 \mathrm{mV}-50,4 \pm$ 21,1 $\mathrm{nA}$, bei einem Klemmpotenzial von $-60 \mathrm{mV}-38,0 \pm 18,2 \mathrm{nA}$ und bei einem Klemmpotenzial von $-30 \mathrm{mV}-27,9 \pm 17,3 \mathrm{nA}$ (Abbildung 10B).

Das Umkehrpotenzial der in Abwesenheit von Succinat gemessenen Ströme beträgt $-34,0 \pm 3,2 \mathrm{mV}$. Es verschiebt sich nach Applikation von $1 \mathrm{mM}$ Succinat in ORi auf $-19,2 \pm 6,3 \mathrm{mV}$. Das Nullstrompotenzial der Succinat-induzierbaren Ströme liegt im Bereich >+30 mV, also im Bereich des Umkehrpotenzials von Natrium. Dies zeigt, dass die Ströme hauptsächlich von Natrium-lonen getragen werden.

Durch Applikation von Succinat steigt in hNaDC-3-exprimierenden Oozyten die Leitfähigkeit $(\mathrm{g})$ der Oozyten an. Diese beträgt bei $-90 \mathrm{mV}$ in Abwesenheit von Succinat 0,7 $\pm 0,1 \mu \mathrm{S}$ und steigt nach Gabe von $1 \mathrm{mM}$ Succinat auf 1,3 0,2 $\mu \mathrm{S}$ an (Abbildung 11). Die entsprechenden Werte bei $-60 \mathrm{mV}$ betragen $0,5 \pm 0,1 \mu \mathrm{S}$ und 1,2 $\pm 0,2 \mu \mathrm{S}$ (Abbildung 12).

A

$$
p<0,01
$$

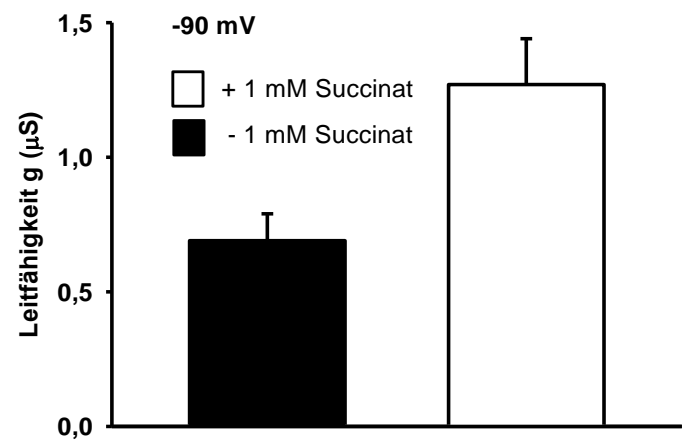

B

$$
p>0,05
$$

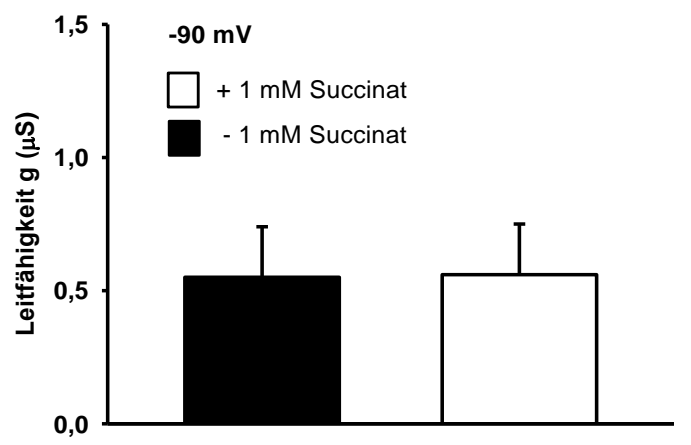

Abbildung 11: Leitfähigkeiten in An-und Abwesenheit von 1mM Succinat bei -90 mV (A) hNaDC-3 exprimierenden Oozyten und (B) Wasser-injizierten Kontrolloozyten. 
A

$p<0,01$

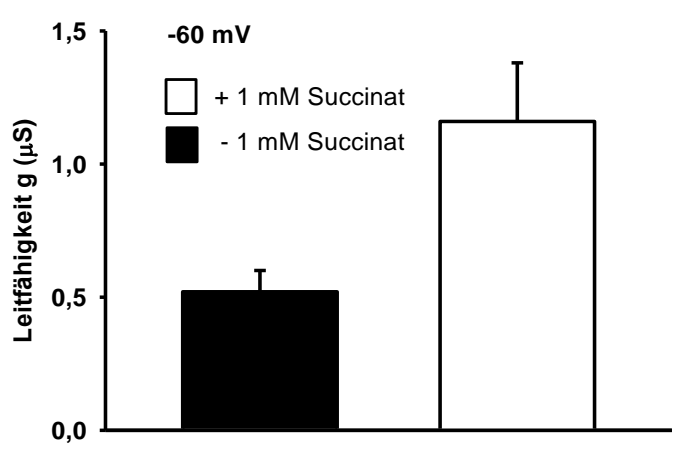

B

$p>0,05$

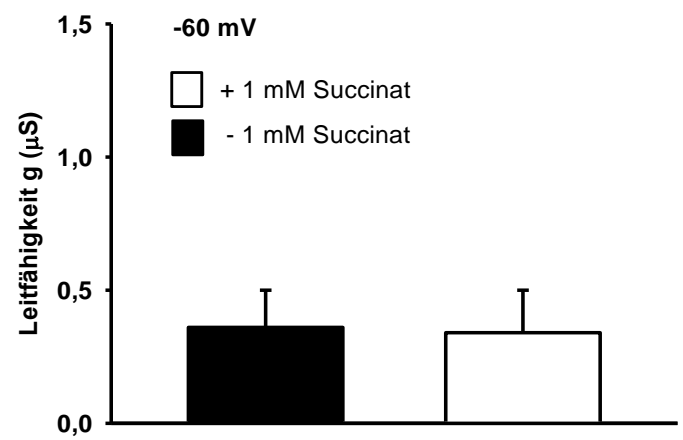

Abbildung 12: Leitfähigkeiten in An- und Abwesenheit von $1 \mathrm{mM}$ Succinat bei -60 mV in (A) hNaDC-3-exprimierenden Oozyten (B) Wasser-injizierten Kontrolloozyten.

Um Einflüsse von Succinat auf endogene Ströme und Leitfähigkeiten der Oozyten auszuschließen, wurden die Versuche an Wasser-injizierten Oozyten wiederholt (Abbildungen 11B, 12B und 13). Dabei wurden die Wasser-injizierten Oozyten mit der gleichen Lösungszusammensetzung perfundiert wie die hNaDC-3-injizierten Oozyten. Diese Kontrollmessungen sind in Abbildung 13 zu sehen. Im Gegensatz zu den Versuchen mit hNaDC-3-exprimierenden Oozyten konnten an Wasser-injizierten Oozyten keine signifikanten Differenzströme nach Gabe von $1 \mathrm{mM}$ Succinat nachgewiesen werden (Abbildung 13B). Dementsprechend wurde auch nur eine geringfügige, jedoch nicht signifikante Verschiebung der Umkehrpotenziale von -40,7 $\pm 6,2 \mathrm{mV}$ auf $-41,0 \pm 6,2 \mathrm{mV}$ beobachtet. Ein Anstieg der Leitfähig konnte bei Wasser-injizierten Oozyten unter Succinatapplikation ebenfalls nicht beobachtet werden. Die Leitfähigkeiten betrugen bei -90 mV 0,6 0,2 $\mu \mathrm{S}$ ohne Succinat und 0,6 $\pm 0,2 \mu \mathrm{S}$ mit Succinat, bei $-60 \mathrm{mV} 0,4 \pm 0,4 \mu \mathrm{S}$ ohne Succinat und $0,4 \pm 0,2 \mu$ mit Succinat (Abbildung 11B und 12B). 
A

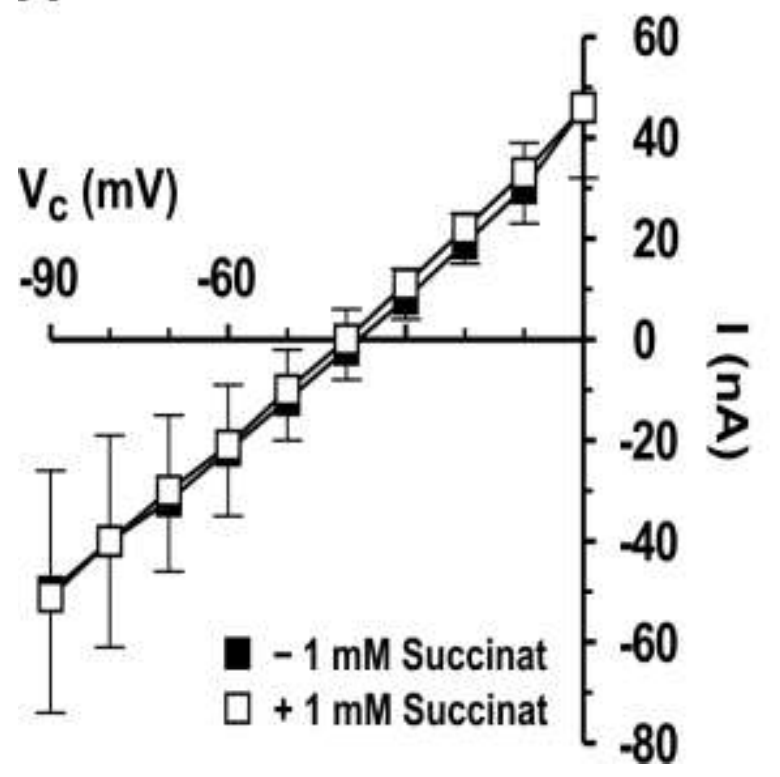

B

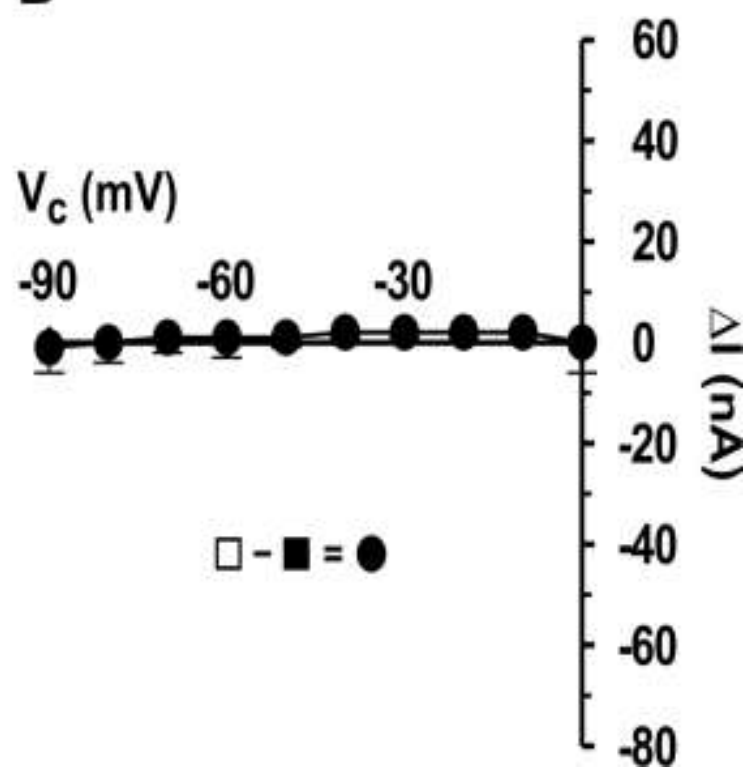

Abbildung 13: I-V-Kennlinien in Wasser-injizierten Oozyten. A: I-V-Kennlinien in ORI in Abund Anwesenheit von $1 \mathrm{mM}$ Succinat. B. Resultierende Differenzströme $(\Delta \mathrm{l})$. Die Abbildung stellt Mittelwerte aus Messungen an 7 Oozyten von 7 Spendertieren dar.

\subsection{Wechselwirkungen von Furosemid und Succinat mit dem hNaDC-3}

Zunächst wurde untersucht, ob es beim humanen NaDC-3 zu einer Hemmung des Succinat-Transportes in Anwesenheit von Furosemid kommt. Dazu wurden zwei verschiedene Versuchsmethoden verwendet. Zum einen wurde die Hemmung an Hand eines Aufnahme-Versuches mit $\left[{ }^{14} \mathrm{C}\right]$-markiertem Succinat in $\mathrm{Ab}$ - und Anwesenheit von Furosemid durchgeführt (Abbildung 14). Zum anderen wurde die Hemmung des durch Succinat induzierbaren Stromes bei gleichzeitiger Gabe von Furosemid bei einem Klemmpotenzial von -60 mV gemessen (Abbildung 15).

\subsubsection{Hemmung der $\left[{ }^{14} \mathrm{C}\right]$ Succinat-Aufnahme durch Furosemid}

Die Messungen ergaben eine Hemmung der $\left[{ }^{14} \mathrm{C}\right]$ Succinat-Aufnahme in Anwesenheit von $1 \mathrm{mM}$ Furosemid von ca. 40\%. In Abbildung 14 sind zunächst die Ergebnisse der Versuche mit der $\left[{ }^{14} \mathrm{C}\right]$ Succinat-Aufnahme-Technik dargestellt. Die Aufnahmen der 
einzelnen Versuchstage wurden normiert, da die $\left[{ }^{14} \mathrm{C}\right]$ Succinat-Aufnahme je nach Expression der Oozyten sehr starken Schwankungen unterlagen.

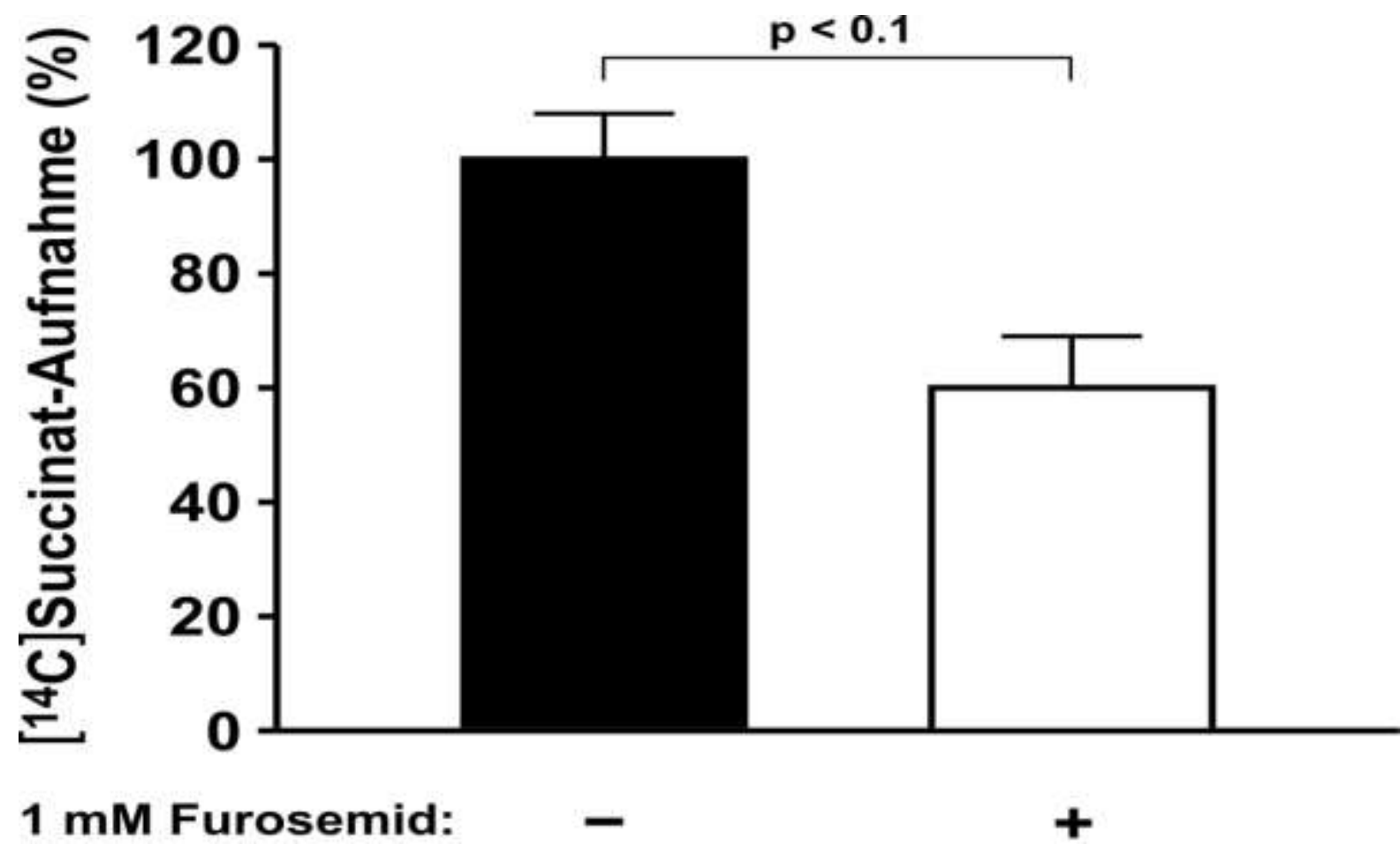

Abbildung 14: Einfluss von $1 \mathrm{mM}$ Furosemid auf die Aufnahme von $\left[{ }^{14} \mathrm{C}\right]$-markierten Succinat. Der schwarze Balken steht für die Aufnahme in Abwesenheit von 1,0 mM Furosemid und der weiße Balken für die Aufnahme in Anwesenheit von 1,0 mM Furosemid. Die Abbildung zeigt Mittelwerte aus 3 Messungen mit jeweils 10 Oozyten pro Versuchsbedingungen. Die Werte sind bereits um die Aufnahmen in Wasser-injizierten Oozyten korrigiert. Zur besseren Vergleichbarkeit der Ergebnisse sind die Aufnahmen in Abwesenheit von Furosemid auf 100\% gesetzt und die Aufnahmen in Anwesenheit von 1 mM Furosemid darauf bezogen.

\subsubsection{Hemmung des Succinat-induzierbaren Stromes durch Furosemid}

Insgesamt ergaben die Messungen mit der Zwei-Elektroden-Klemm-Technik ähnliche Ergebnisse wie die Messungen zur Hemmung von $\left[{ }^{14} \mathrm{C}\right]$-markiertem Succinat durch Furosemid. Die Ergebnisse sind zur Veranschaulichung als Strickleitermodell in Abbildung 15 dargestellt.

Die durch Succinat induzierten Differenzströme reduzierten sich unter Furosemidgabe in 3 der 7 Messreihen deutlich. Jeweils bei einer Klemmspannung 
von -60 mV kam es zu einer Reduzierung von -74,0 nA auf $+4,0 \mathrm{nA}$, von -49,0 nA auf -26,0 nA und von -26,0 nA auf -14,0 nA. In zwei Messungen kommt es lediglich zu einer geringen Hemmung -28,0 nA auf -20,0 nA bzw. von -29,0 nA auf -21,0 nA. In den restlichen Messungen kommt es durch Furosemid zu keiner Hemmung bzw. sogar zu einem leichten Anstieg der Ströme (von -13,0 nA auf -14,0 nA und von $17,0$ nA auf $-20,0 n A)$.

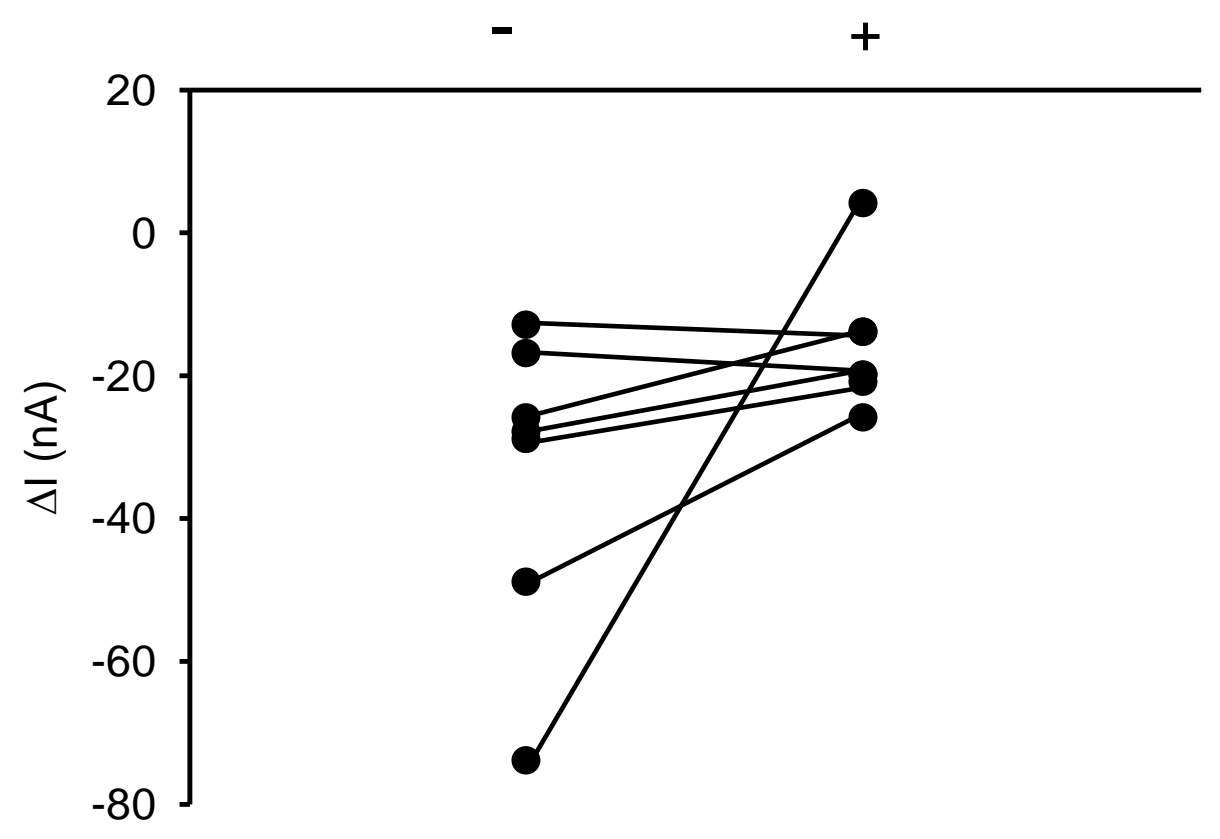

Abbildung 15: Änderungen des Succinat-assoziierten Stromes in Ab- (-) und Anwesenheit von Furosemid (+). Jedes Symbol steht für den Differenzstrom, der sich bei einem Klemmpotenzial von $-60 \mathrm{mV}$ ergab.

Sowohl die Messungen mit der Zwei-Elektroden-Klemm-Technik als auch die Messungen zur Hemmung von $\left[{ }^{14} \mathrm{C}\right]$-markierten Succinat durch Furosemid bestätigen somit die Annahme einer Hemmung des Succinattransportes über den $\mathrm{hNaDC}-3$ bei Anwesenheit von $1 \mathrm{mM}$ Furosemid. 


\subsubsection{Einfluss aufsteigender Furosemidkonzentrationen auf den Succinat - induzierbaren Strom}

Um die Hemmung des Succinattransportes über den hNaDC-3 durch Furosemid genauer zu klassifizieren, wurde nun der Einfluss von verschiedenen Furosemidkonzentrationen auf den Succinattransport untersucht. Es wurden Furosemidkonzentrationen von $0,1 \mathrm{mM}, 0,5 \mathrm{mM}, 1,0 \mathrm{mM}$ und $5 \mathrm{mM}$ bei einer konstant gehaltenen Succinatkonzentration von 1,0 mM appliziert. In allen Versuchen wurden alle Konzentrationen an jeweils einer Oozyte getestet. Insgesamt wurden 4 hNaDC-3-exprimierende Oozyten von 4 Spendertieren untersucht. Alle Oozyten wurden zunächst auf den Succinat-induzierbaren Strom bei einer Konzentration von 1,0 mM ohne Zugabe von Furosemid untersucht, um die Expression zu überprüfen und einen Referenzwert für die folgenden Messungen zu bekommen. Bei einem Klemmpotenzial von $-90 \mathrm{mV}$ lag der Mittelwert, der durch Succinat induzierten Ströme, bei $-37,3 \pm 15,8 \mathrm{nA}$, bei $-60 \mathrm{mV}$ bei $-30,0 \pm 10,4 \mathrm{nA}$ und bei $-30 \mathrm{mV}$ ergaben sich Differenzströme von $-24,3 \pm 8,0 \mathrm{nA}$.

Bei Applikation von Furosemidkonzentrationen von 0,1 und $0,5 \mathrm{mM}$ ergab sich keine nennenswerte Hemmung der durch Succinat induzierbaren Ströme. So erhielt man bei einer Zugabe von 0,1 mM Furosemid bei einem Klemmpotenzial von $-90 \mathrm{mV}$ Einwärtsströme von $-37,0 \pm 10,2 \mathrm{nA}$, bei $-60 \mathrm{mV}$ von $-29,8 \pm 6,8$ und bei $-30 \mathrm{mV}$ wurden Einwärtsströme von $-22,0 \pm 6,5 \mathrm{nA}$ gemessen. Ein ähnliches Bild ergibt sich bei Konzentrationen von 0,5 mM Furosemid. Man erhält Einwärtsströme von -41,3 \pm 11,9 nA bei einem Klemmpotenzial von $-90 \mathrm{mV}$ bzw. $-31,8 \pm 8,0 \mathrm{nA}$ bei $-60 \mathrm{mV}$ und bei einem Klemmpotenzial von $-30 \mathrm{mV}$ wurden durch $0,5 \mathrm{mM}$ Furosemid Einwärtsströme von -21,8 \pm 6,0 nA erzielt. Dagegen lässt die gleichzeitige Applikation von $1 \mathrm{mM}$ Succinat und $1 \mathrm{mM}$ Furosemid eine Hemmung der durch Succinat induzierbaren Ströme in den hNaDC-3-exprimierenden Oozyten erkennen. Bei einem Klemmpotenzial von - $90 \mathrm{mV}$ war der Einwärtsstrom -32,0 \pm 5,2 nA, bei - $60 \mathrm{mV}-23,0$ $\pm 3,5 \mathrm{nA}$ und bei $-30 \mathrm{mV} 15,8 \pm 2,3 \mathrm{nA}$. Das entspricht einer prozentualen Verringerung der zu induzierenden Ströme bei einer zusätzlichen Gabe von $1 \mathrm{mM}$ Furosemid von $14 \%$ bei einem Klemmpotenzial von $-90 \mathrm{mV}, 23 \%$ bei $-60 \mathrm{mV}$ und $35 \%$ bei $-30 \mathrm{mV}$. 
Noch deutlicher zeigt sich die Hemmung bei einer Applikation von 5,0 mM Furosemid. Hier betrugen die Substrat-assoziierten Einwärtsströme bei $-90 \mathrm{mV}$ nur noch $-28,3 \pm 11,5 \mathrm{nA}$, bei $-60 \mathrm{mV}-16,5 \pm 5,90 \mathrm{nA}$ und bei $-30 \mathrm{mV}-6,5 \pm 3,2 \mathrm{nA}$. Es kommt also zu einer deutlichen Hemmung im Vergleich zu der zuvor durch alleinige Perfusion mit 1,0 mM Succinat induzierten Einwärtsströme um $24 \%$ bei -90 mV, um $45 \%$ bei $-60 \mathrm{mV}$ und um $73 \%$ bei $-30 \mathrm{mV}$. Zur Verdeutlichung sind die besprochenen Ergebnisse in Abbildung 16 noch einmal graphisch dargestellt.

\section{$\mathrm{V}_{\mathrm{c}}(\mathrm{mV})$}

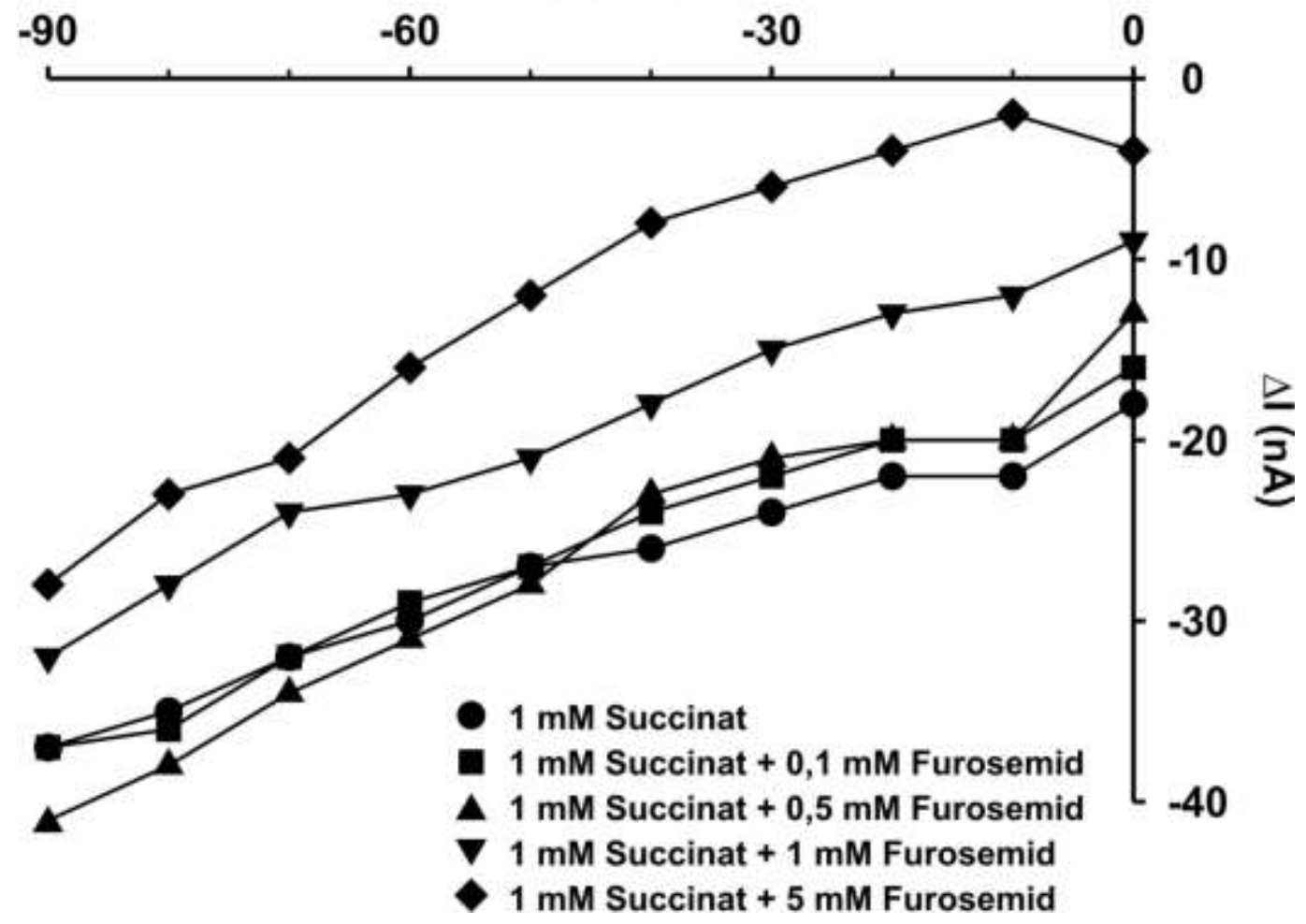

Abbildung 16: Hemmung der Succinat-induzierbaren Ströme durch aufsteigende Konzentrationen von Furosemid. Dargestellt sind die durch 1,0 mM Succinat induzierten Ströme in Abwesenheit und Anwesenheit der verschiedenen Furosemidkonzentrationen von $0,1 \mathrm{mM}, 0,5 \mathrm{mM}, 1,0 \mathrm{mM}$ und 5,0 mM in hNaDC-3-exprimierenden Oozyten. Nur bei den Konzentrationen von 1,0 mM und 5,0 mM Furosemid kommt es zu einer eindeutigen Reduzierung der durch Succinat induzierten Einwärtsströme. Die übrigen gemessenen Konzentrationen zeigten keinen signifikanten Einfluss auf die durch Succinat zu induzierenden Ströme. Auf die Standardabweichungen wurde aus Gründen der Übersichtlichkeit verzichtet. 
Somit lässt sich sowohl eine konzentrationsabhängige als auch eine potenzialabhängige Hemmung von Furosemid auf den Succinat-induzierten Strom feststellen.

Die Versuche an Wasser-injizierten Kontrolloozyten zeigten keine induzierbaren Ströme durch die applizierten Testsubstanzen. Sie sind aus Gründen der Übersichtlichkeit in Abbildung 16 nicht dargestellt.

\subsection{Translokation von Furosemid über den hNaDC-3}

Nachdem die Hemmung des Transportes von Succinat durch Furosemid über den hNaDC-3 gezeigt werden konnte, sollte nun die Frage geklärt werden, ob Furosemid lediglich einen Einfluss auf die Bindungsstelle von Succinat am hNaDC-3 hat, oder ob es selber durch den hNaDC-3 transportiert werden kann.

Auch bei dieser Messreihe wurden die hNaDC-3-exprimierenden Oozyten zunächst auf die Succinat-induzierbaren Ströme bei einer Konzentration von 1 mM untersucht. Anschließend wurden die Ströme gemessen, die sich durch alleinigen Zusatz von 1,0 mM Furosemid zu der ORI-Lösung ergaben. Graphisch ist dies in Abbildung 17 dargestellt.

Die Messungen ergaben kleine durch Furosemid induzierbare Einwärtsströme, die sich bei einem Klemmpotenzial von ca. $-40 \mathrm{mV}$ in Auswärtsströme umkehrten. 1,0 mM Furosemid induzierte bei $-90 \mathrm{mV}$ Einwärtsströme von -13,0 \pm 5,2 nA und bei -60 $\mathrm{mV}$ Ströme von $-4,7 \pm 3,8 \mathrm{nA}$. Bei Klemmpotenzialen von $-30 \mathrm{mV}$ bzw. $-10 \mathrm{mV}$ dagegen kommt es zu Auswärtsströmen von 2,4 \pm 5,0 nA bzw. 6,0 \pm 4,7 nA. Im Gegensatz dazu zeigten die Wasser-injizierten Kontrolloozyten bei keinem der getesteten Klemmpotenziale signifikante Ströme unter Zusatz von $1 \mathrm{mM}$ Furosemid.

Die Leitfähigkeiten erhöhten sich unter Furosemidgabe von 0,9 $\pm 0,3 \mu S$ auf $1,0 \pm 0,3$ $\mu \mathrm{S}$ bei einer Klemmspannung von $-90 \mathrm{mV}$ bzw. von $0,7 \pm 0,3 \mu \mathrm{S}$ auf $0,8 \pm 0,3 \mu \mathrm{S}$ bei $-60 \mathrm{mV}$ (Abbildung 18). 


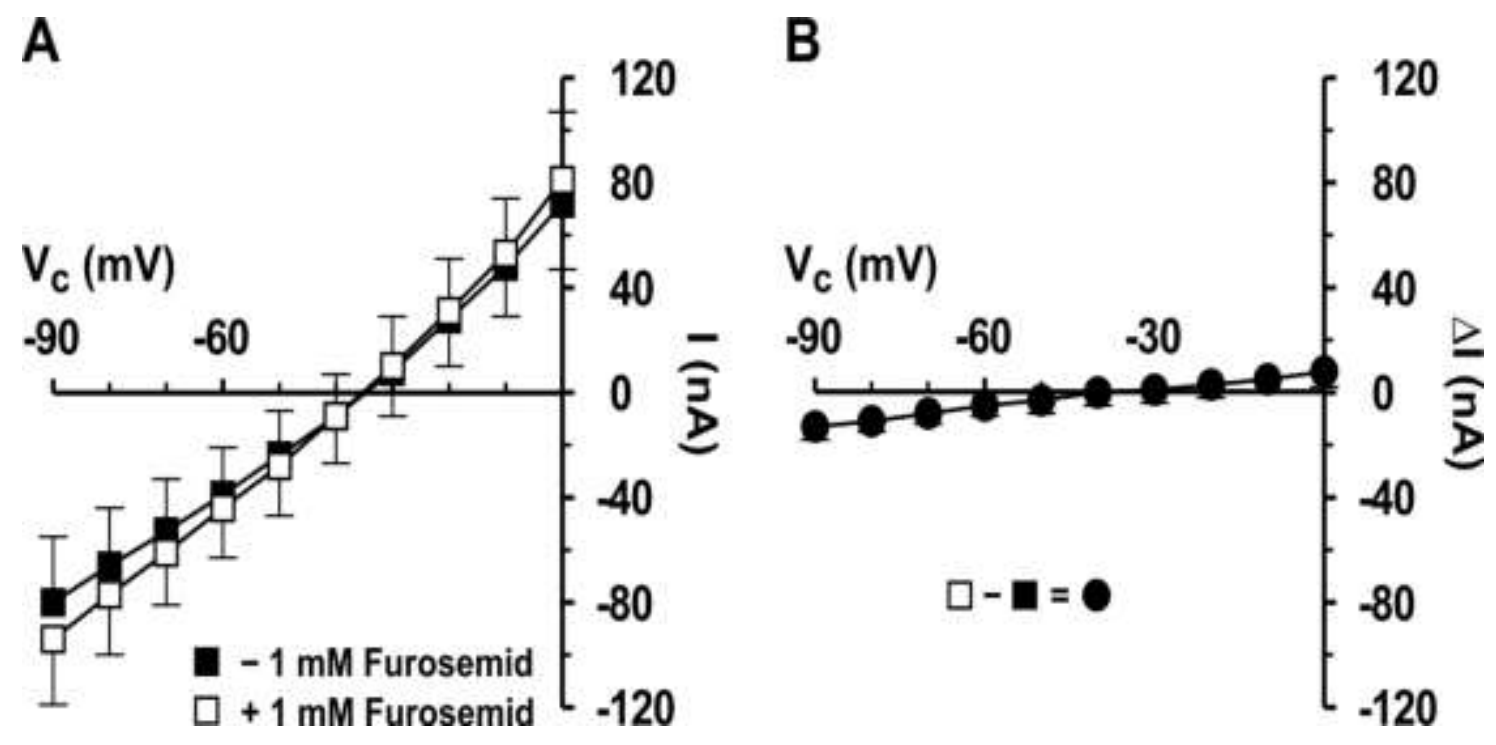

Abbildung 17: Illustration der I-V-Kennlinien (A) der ORI-Lösung in Abwesenheit (gefüllte Quadrate) und in Anwesenheit von 1,0 mM Furosemid (offene Quadrate) im Bereich von -90 bis $0 \mathrm{mV}$ bei einem $\mathrm{pH}$-Wert von 7,5 an $\mathrm{hNaDC}$-3-exprimierenden Oozyten. Dargestellt sind Mittelwerte von 9 verschieden Oozyten aus 8 Fröschen. (B) Darstellung der durch 1,0 mM Furosemid induzierten potenzialabhängigen Differenzströme als Mittelwerte. Durch 1,0 mM Furosemid kommt es zu einem Einwärtsstrom bei negativen Klemmpotenzialen, der sich im Bereich zwischen $-40 \mathrm{mV}$ und $-30 \mathrm{mV}$ in einen Auswärtsstrom umwandelt.

A

$$
p<0,01
$$

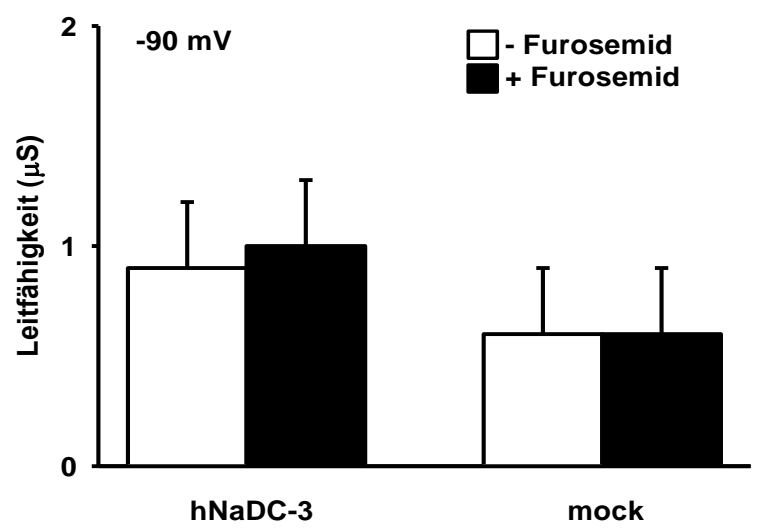

B

$$
\mathrm{p}<0,01
$$$$
p>0,05
$$

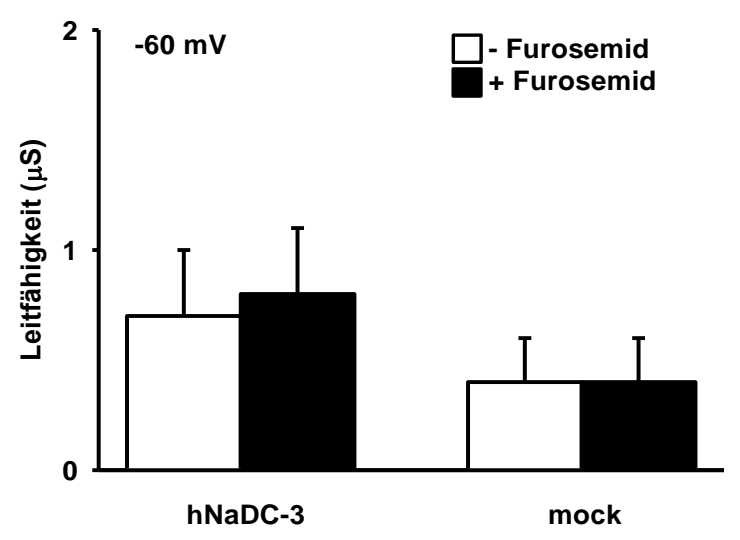

Abbildung 18: Veränderung der Leitfähigkeit unter Perfusion (schwarze Balken) und ohne Perfusion (weiße Balken) mit $1 \mathrm{mM}$ Furosemid an hNaDC-3-exprimierenden Oozyten bei einer Klemmspannung von $-90 \mathrm{mV}(\mathrm{A})$ und $-60 \mathrm{mV}(\mathrm{B})$. jeweils im Vergleich zu Wasserinjizierten Oozyten (mock). Berechnet aus Messreihen an 9 hNaDC-3-injizierten Oozyten und 7 Wasser-injizierten Oozyten (mock) von jeweils 8 bzw. 7 Spendertieren. 
Insgesamt sind die durch 1,0 mM Furosemid hervorgerufenen potenzialabhängigen Ströme in hNaDC-3-exprimierenden Oozyten im Vergleich zu den durch Succinat induzierten Strömen deutlich geringer (Abbildung 19). So erreichen die bei -90 mV durch Furosemid induzierten Ströme nur $26 \%$ der durch Succinat induzierten Differenzströme und bei einem Klemmpotenzial von - $60 \mathrm{mV}$ sogar nur noch $12 \%$ der Succinat-induzierbaren Ströme.

Die Kontrollmessung an Wasser-injizierten Oozyten zeigt weder bei einer Applikation mit 1,0 mM Furosemid noch bei 1,0 mM Succinat nennenswerte Differenzströme (Abbildung 19B).

A

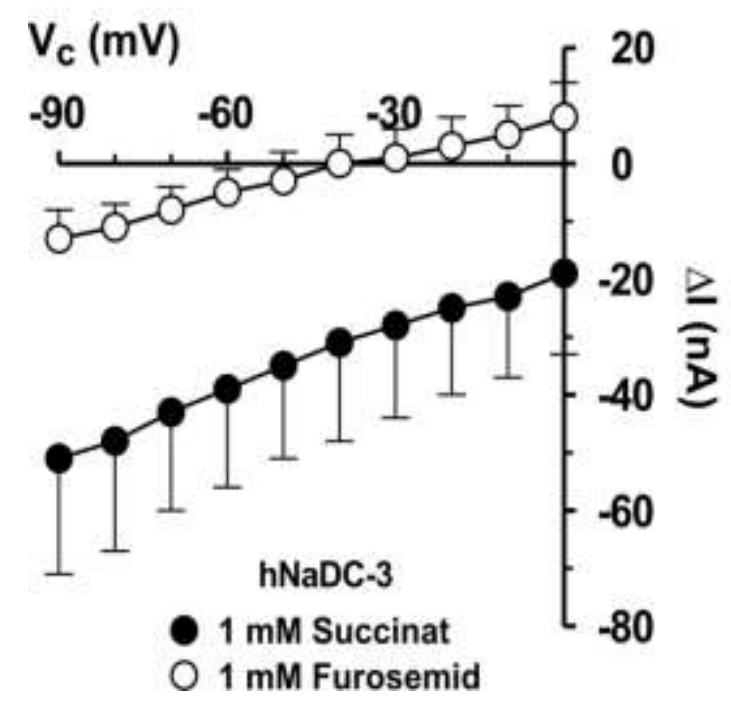

B

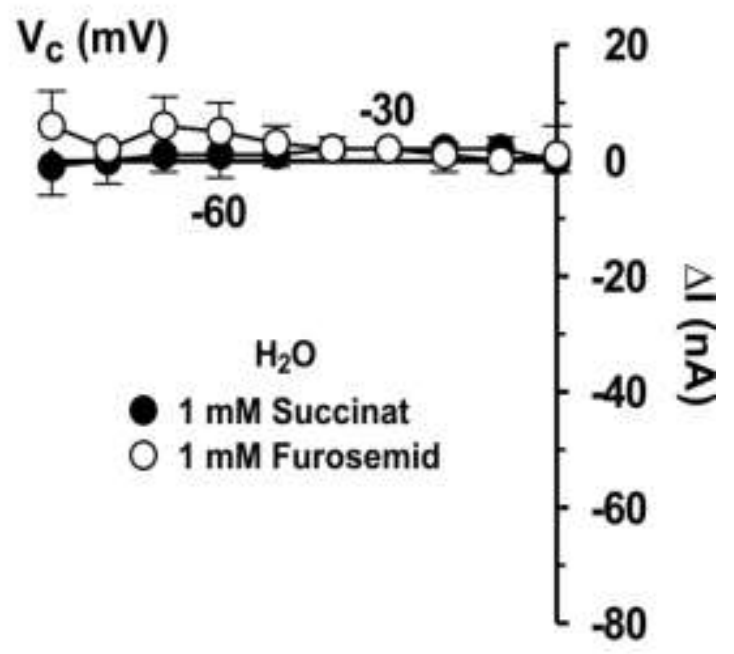

Abbildung 19: Vergleich der Amplituden der durch $1 \mathrm{mM}$ Succinat ( geschlossene Kreise) und $1 \mathrm{mM}$ Furosemid ( offene Kreise ) induzierten Ströme bei hNaDC-3-exprimierenden Oozyten (A) Die entsprechenden Messungen an den Wasser-injizierten Kontrolloozyten sind in (B) dargestellt. Erhebung der Daten aus insgesamt 31 Messreihen an 16 hNaDC-3exprimiereden Oozyten und 15 Wasser-injizierten Oozyten.

\subsubsection{Natriumabhängigkeit des Furosemid-induzierbaren Stromes}

Als nächstes wurde die Natriumabhängigkeit der Furosemid-induzierbaren Ströme untersucht. Die Überprüfung der Natriumabhängigkeit dient als weiterer Beleg für den Transport eines Substrates über den hNaDC-3. 
Die bei dieser Versuchsreihe erzielten Ergebnisse ließen eine Aufhebung der durch 1,0 mM Furosemid induzierten Ströme bei Ersatz des Natriums durch N-methyl-DGlucamin (NMDG) erkennen. Bei -90 mV ergaben sich mit der Natrium-freien ORiLösung Mittelwerte von 3,3 $\pm 3,0 \mathrm{nA}$ und bei $-30 \mathrm{mV}$ von 1,7 $\pm 3,0 \mathrm{nA}$, bei Perfusion mit der Natrium-haltigen ORi-Lösung ergaben sich dagegen Furosemid-induzierbare Ströme von $-16,7 \pm 2,5$ bei $-90 \mathrm{mV}$ und $-4,3 \pm 2,9 \mathrm{nA}$ bei $-30 \mathrm{mV}$ (Abbildung $20 \mathrm{~B}$ offene Kreise).

Zur Ergänzung wurden ebenfalls Untersuchungen mit $1 \mathrm{mM}$ Succinat unter Natriumfreien Bedingungen durchgeführt. Diese zeigten ebenfalls eine Aufhebung der Succinat-induzierten Ströme unter $\mathrm{Na}^{+}$-Abwesenheit (Abbildung 20A). Alle Wasserinjizierten Kontrolloozyten zeigten weder mit noch ohne Natrium zu messende Ströme durch die applizierten Substrate.

A

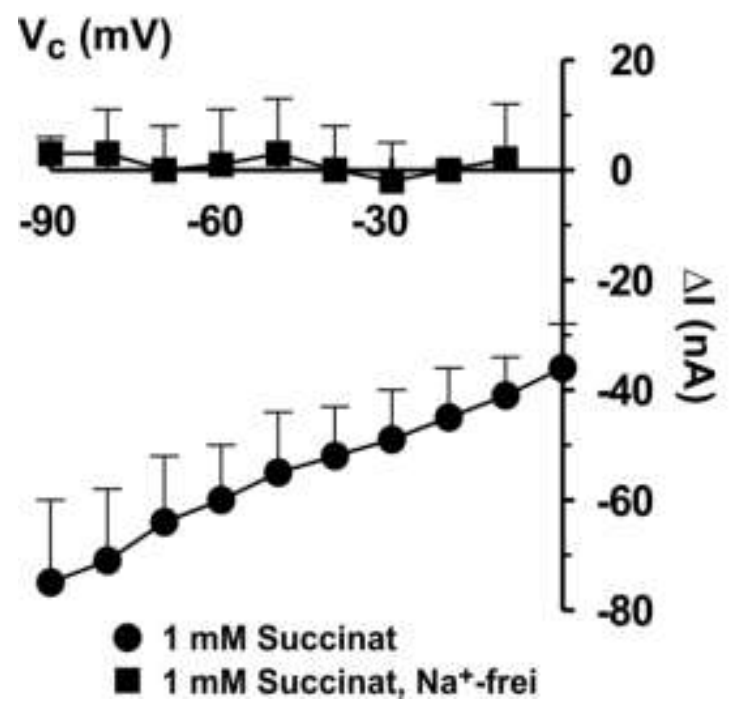

B

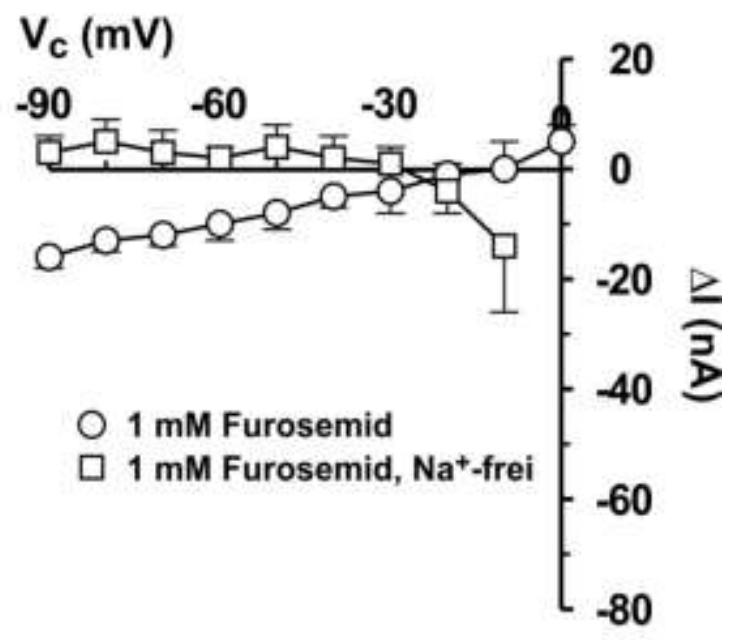

Abbildung 20: Vergleich der Ströme, die durch 1,0 mM Succinat bzw. 1,0 mM Furosemid in An- und Abwesenheit von Natrium induziert wurden. (A) $1 \mathrm{mM}$ Succinat induziert potenzialabhängige Einwärtsströme (geschlossene Kreise), die unter Natriumersatz durch NMDG zum Erliegen gekommen sind (geschlossene Quadrate). (B) Die Furosemidinduzierbaren Ströme (offene Kreise) können ebenfalls unter NMDG (offene Quadrate) nicht mehr nachgewiesen werden. Die Messdaten wurden an $6 \mathrm{hNaDC}-3$-injizierten und 3 Wasser-injizierten Oozyten aus 3 Spendertieren erhoben. 
Somit zeigte sich eine Natriumabhängigkeit des Transportes von Furosemid mittels des hNaDC-3 und ist damit als ein weiteres Indiz für den Transport von Furosemid über den hNaDC-3 zu werten.

\subsubsection{Interaktionen von Lithium und Furosemid}

Um die Beeinflussung von Lithium auf den Transport von Furosemid über den hNaDC-3 zu testen, wurden Messungen an 4 Oozyten von 3 verschieden Spendertieren durchgeführt.

Die Messungen ergaben, dass es beim $h N a D C-3$ durch Lithium nur bei Klemmspannungen von bis ca. $-60 \mathrm{mV}$ zu einer nachweisbaren Hemmung, der durch Furosemid induzierten Differentialströme, kommt. Der gemessene Strom reduziert sich bei einer Klemmspannung von $-90 \mathrm{mV}$ von -10,8 \pm 3,8 nA bei einer Gabe von 2 $\mathrm{mM}$ Lithium auf $-4,5 \pm 9,3 \mathrm{nA}$ und bei $-60 \mathrm{mV}$ reduzieren sich die zu erzielenden Ströme unter Lithiumgabe von $-2,80 \pm 3,30 \mathrm{nA}$ auf $-0,8 \pm 5,3 \mathrm{nA}$. Bei einer Klemmspannung von $-30 \mathrm{mV}$ kommt es bei einer alleinigen Gabe von $1 \mathrm{mM}$ Furosemid zu einem Auswärtsstrom von 5,5 \pm 5,7 nA und bei einer zusätzlichen Gabe von 2 mM Lithium zu einem gemessen Differenzstrom von 6,0 \pm 5,6 nA.

Auch bei den zur Kontrolle gemachten Messungen mit Succinat kam es durch Lithium nur zu sehr geringen Hemmungen des Succinattransportes. In Abbildung 21 sind die Versuche der Interaktion des Lithiums mit Succinat und Furosemid graphisch dargestellt. 

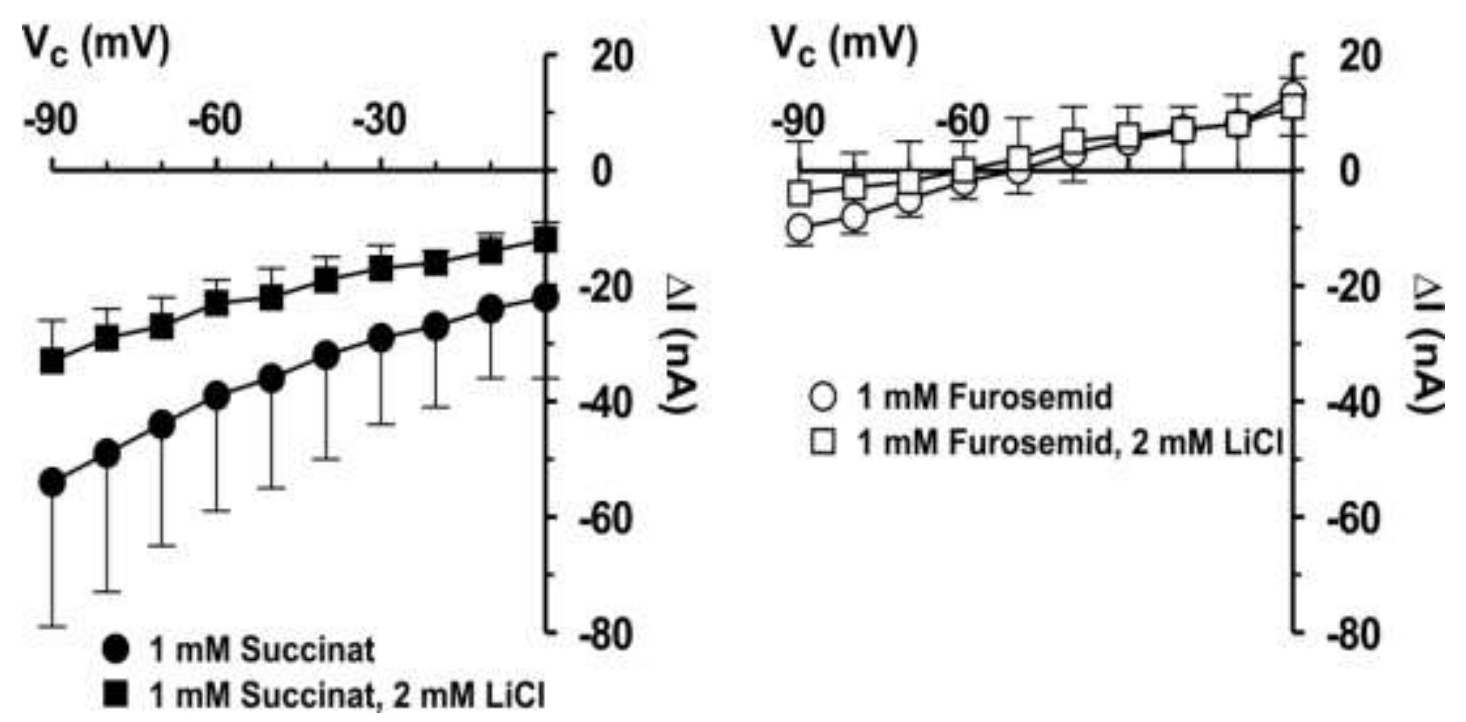

Abbildung 21: Einfluss von Lithium auf die Succinat- und Furosemid-assoziierten Ströme. Gezeigt sind in die Differenzströme (A) für Succinat (schwarze Symbole) und (B) für Furosemid (weiße Symbole) in Ab- (Kreise) und Anwesenheit (Quadrate) von 2 mM Lithium. Es handelt sich um gepaarte Messungen (4 Oozyten von 3 Spendertieren), bei denen zuerst die Succinat-induzierten Ströme und anschließend die Furosemid-induzierten Ströme in Abund Anwesenheit von Lithium gemessen wurden.

\subsection{Interaktion von Bumetanid mit dem hNaDC-3}

Nachdem die Versuche mit Furosemid zumindest eine geringe Interaktion mit dem hNaDC-3 gezeigt hatten, wollten wir nun untersuchen, ob auch das strukturverwandte Schleifendiuretikum Bumetanid mit dem hNaDC-3 interagiert. Dazu wurden Versuche an 5 verschiedenen hNaDC-3-exprimierenden Oozyten aus 5 verschiedenen Spenderfröschen mittels der Zwei-Elektroden-Klemm-Technik durchgeführt.

Bei jeder der Messreihen wurden in unterschiedlicher Reihenfolge nacheinander jeweils 0,5 mM Succinat, Furosemid oder Bumetanid gelöst in ORi appliziert. Dabei zeigte sich, dass $0,5 \mathrm{mM}$ Bumetanid ähnliche Differenzströme wie 0,5 mM Furosemid induzierte. Genauso wie bei Furosemid ergab sich auch bei Bumetanid eine Umkehrung des Einwärtsstromes in einen Auswärtsstrom bei Klemmpotenzialen zwischen -50 und $-30 \mathrm{mV}$. Eine Potenzialabhängigkeit ist deutlich erkennbar. Insgesamt waren die Differenzströme im Vergleich zu den durch Succinat erzielten Differenzströmen deutlich geringer. In Abbildung 22 sind diese Ergebnisse graphisch aufgetragen. 


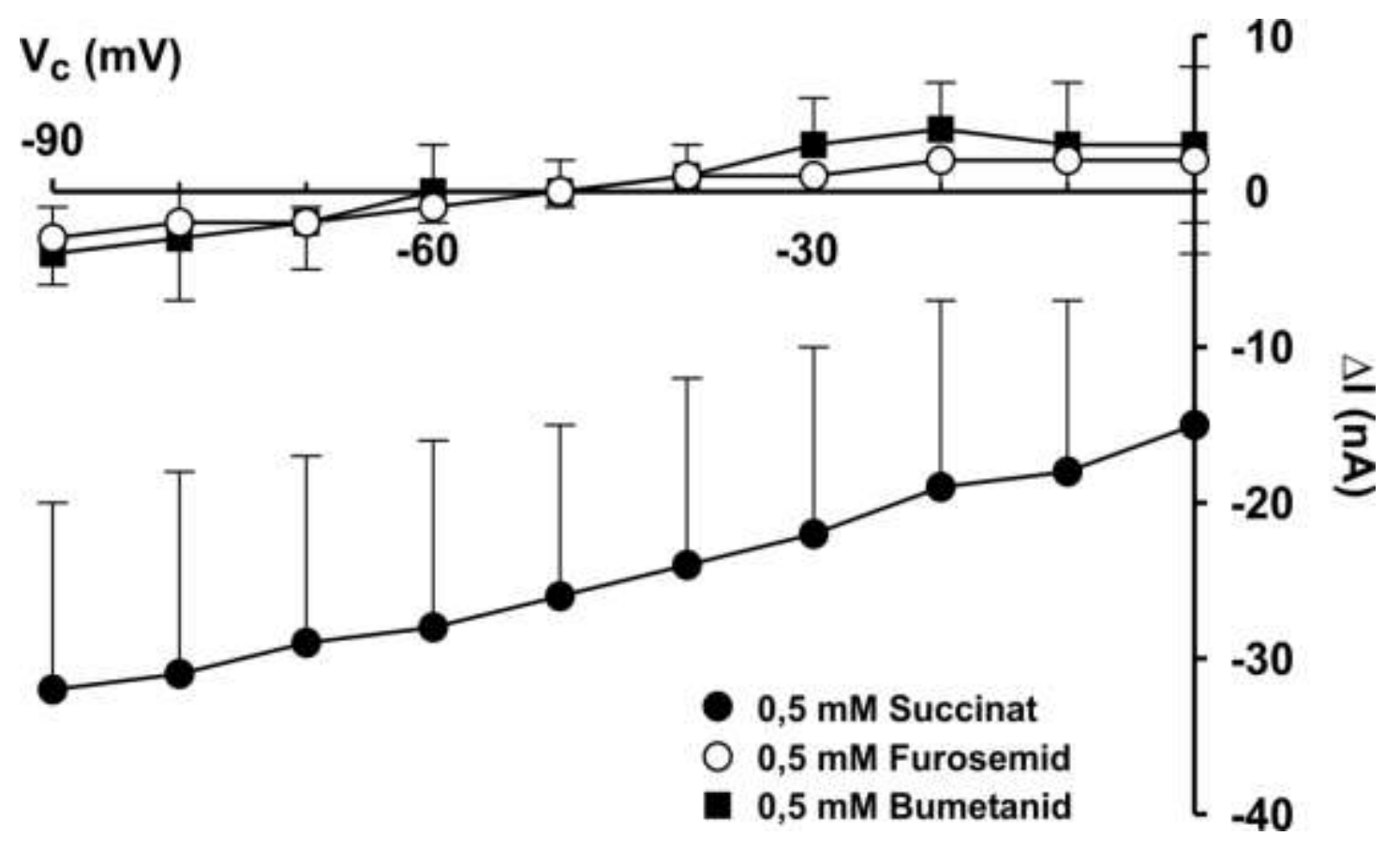

Abbildung 22: Substratspezifität des hNaDC-3 in Bezug auf Schleifendiuretika. Furosemid (offene Kreise) und Bumetanid (geschlossene Quadrate) zeigten bei allen untersuchten Potenzialen vergleichbare Stromamplituden, die allerdings im Vergleich zu den von Succinat hervorgerufenen Strömen sehr gering waren. Dargestellt sind Mittelwerte aus gepaarten Messungen an 5 Oozyten von 5 Donoren.

Die Messungen ergaben für Bumetanid bei einen Klemmpotenzial von $-90 \mathrm{mV}$ Einwärtsströme von $-4,0 \pm 3,0 \mathrm{nA}$, die sich bei $-60 \mathrm{mV}$ auf Differenzströme von $-0,8 \pm$ $3,5 \mathrm{nA}$ reduzierten. Bei einem Haltepotenzial von $-30 \mathrm{mV}$ ergaben sich Auswärtsströme von 3,0 $\pm 3,7$ nA. Die aus den Ergebnissen berechneten Leitfähigkeiten ergaben einen minimalen Anstieg von 0,6 $\pm 0,2 \mu S$ auf $0,7 \pm 0,2 \mu S$ bei $-90 \mathrm{mV}$ und von 0,4 $\pm 0,2 \mu \mathrm{S}$ auf 0,5 $\pm 0,3 \mu \mathrm{S}$ bei $-60 \mathrm{mV}$ (Abbildung 23). Die an drei verschieden Wasser-injizierten Oozyten durchgeführten Kontrollmessungen ergaben keine signifikanten Substrat-mediierten Ströme. 
A

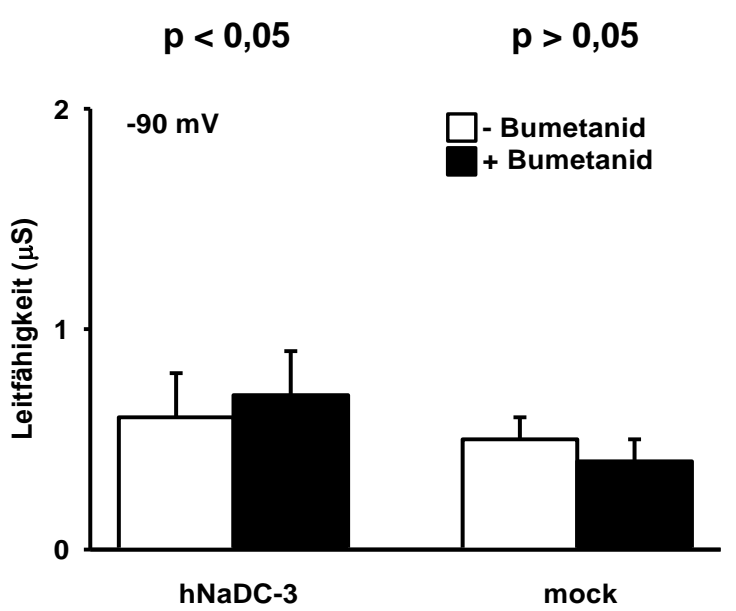

B

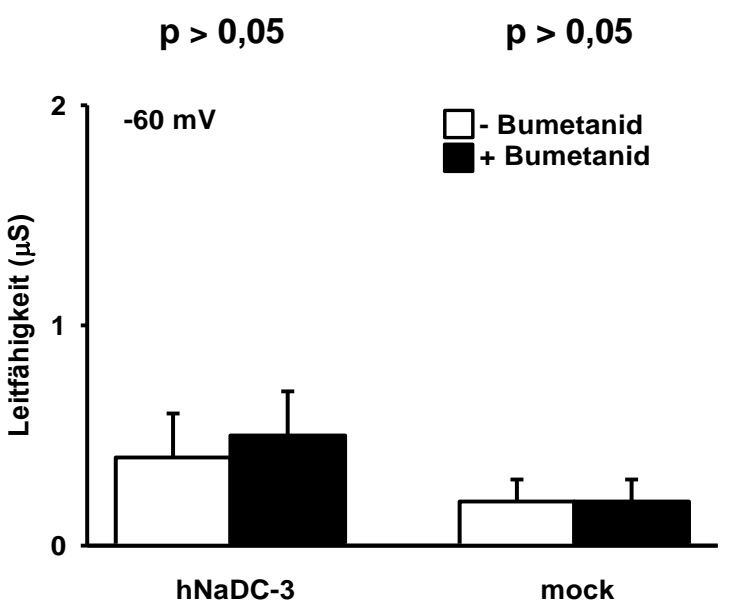

Abbildung 23: Veränderung der Leitfähigkeit unter Perfusion (schwarze Balken) und ohne Perfusion (weiße Balken) mit $1 \mathrm{mM}$ Bumetanid an hNaDC-3-exprimierenden Oozyten bei einer Klemmspannung von $-90 \mathrm{mV}(\mathrm{A})$ und $-60 \mathrm{mV}(\mathrm{B})$, jeweils im Vergleich zu Wasserinjizierten Oozyten. Berechnet aus Messreihen an 5 hNaDC-3-injizierten und 3 Wasserinjizierten Oozyten).

\subsection{Interaktion von Etacrynsäure mit dem hNaDC-3}

Auch in der Versuchsreihe mit Etacrynsäure wurden zum Vergleich Messungen mit 0,5 mM Furosemid und mit 0,5 mM Succinat durchgeführt. Die Versuche wurden mit 4 hNaDC-3-exprimierenden Oozyten von 4 verschiedenen Spendertieren durchgeführt. Die durch Etacrynsäure induzierten Ströme zeigten ähnliche Charakteristika wie die Furosemid-induzierten Ströme. So gab es auch hierbei ein Wechsel von einem Einwärtsströmen in Auswärtsströme mit einem Umkehrpotenzial $E_{\text {rev }}$ im Spannungsklemmbereich zwischen $-40 \mathrm{mV}$ und $-60 \mathrm{mV}$. Insgesamt konnten sogar Ströme geringfügig größerer Amplitude durch Etacrynsäure als durch Furosemid hervorgerufen werden. (Abbildung 24).

Bei einem Klemmpotenzial von $-90 \mathrm{mV}$ wurde durch Konzentrationen von 0,5 mM Etacrynsäure mittlerere Differenzströme von -4,8 $\pm 3,2 \mathrm{nA}$ ermittelt (bei Furosemid $-3,5 \pm 2,5 \mathrm{nA})$. Auch bei $-60 \mathrm{mV}$ kommt es durch 0,5 mM Etacrynsäure noch zu Einwärtsströmen von $-3 \pm 3,7 \mathrm{nA}$ (Furosemid: $-1,5 \pm 1,6$ ) Bei - $30 \mathrm{mV}$ erhielt man einen Auswärtsstrom von $2 \pm 3,3 \mathrm{nA}$. Die Kontrollmessungen an Wasser-injizierten Oozyten ergaben keine von Null verschieden Ströme. 


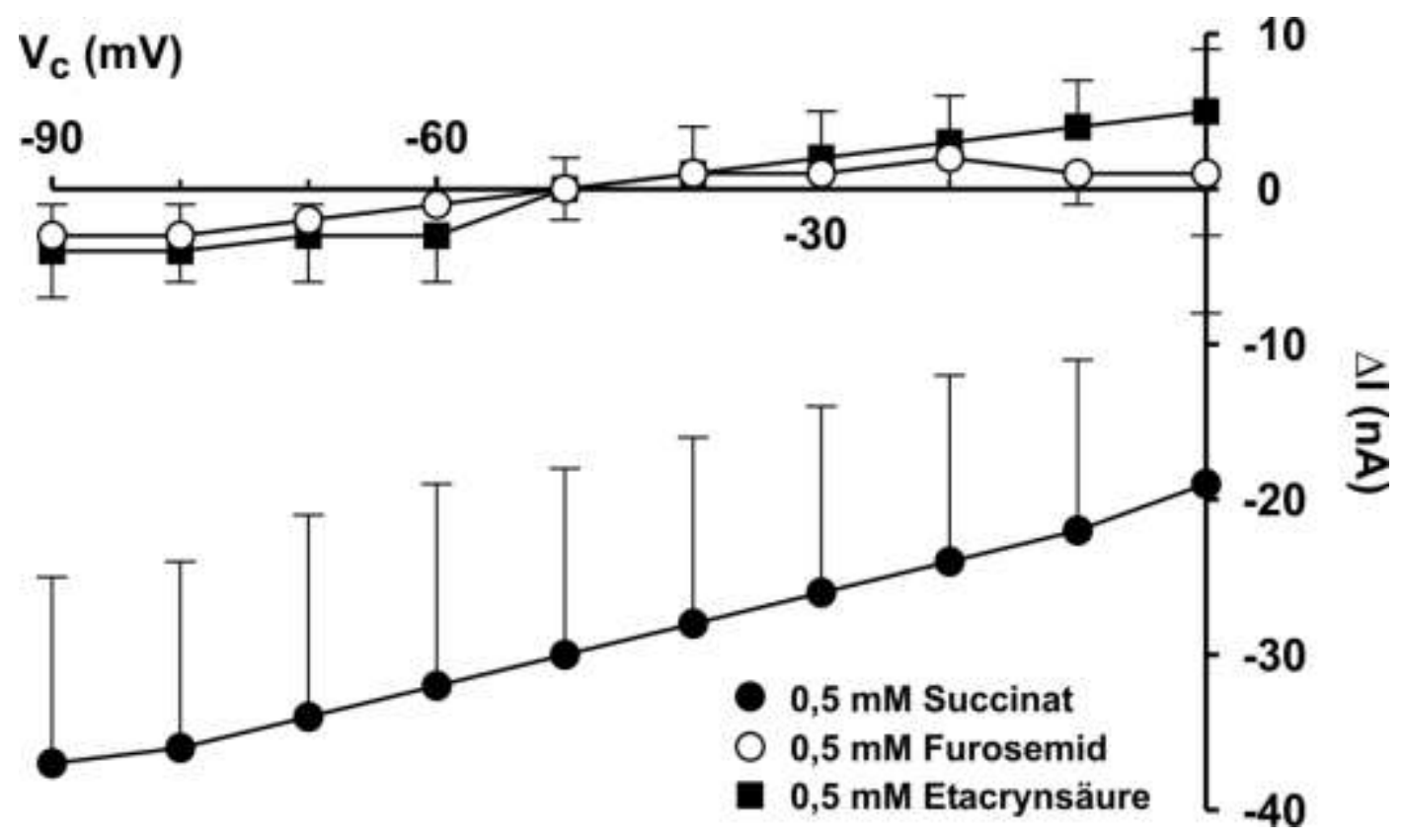

Abbildung 24: Interaktion von Etacrynsäure mit dem hNaDC-3. In gepaarten Experimenten (4 Oozyten von 2 Fröschen) wurden die durch 0,5 mM Succinat (gefüllte Kreise). 0,5 mM Furosemid (offene Kreise) und 0,5 mM Etacrynsäure (Quadrate) hervorgerufenen Ströme miteinander verglichen.

\subsection{Interaktion von Acetazolamid und Sulfanilamid mit dem hNaDC-3}

Die durch 0,5 mM Acetazolamid und 0,5 mM Sulfanilamid hervorgerufenen Differenzströme lagen insgesamt deutlich niedriger als die durch Succinat und Furosemid erzielten Differenzströme. Bei einer Klemmspannung von - $60 \mathrm{mV}$ kommt es durch Acetazolamid zu Einwärtsströmen von $-2,0 \pm 2,6 \mathrm{nA}$ und bei Sulfanilamid zu Einwärtsströmen von -1,2 $\pm 1,4 \mathrm{nA}$. Furosemid erzeugt in den gleichen hNaDC-3exprimierenden Oozyten Einwärtsströme von -3,8 \pm 6,5 nA und Succinat Einwärtsströme von -39,3 $\pm 32,2$ nA. Die Ergebnisse sind in Abbildung 25 graphisch dargestellt. 


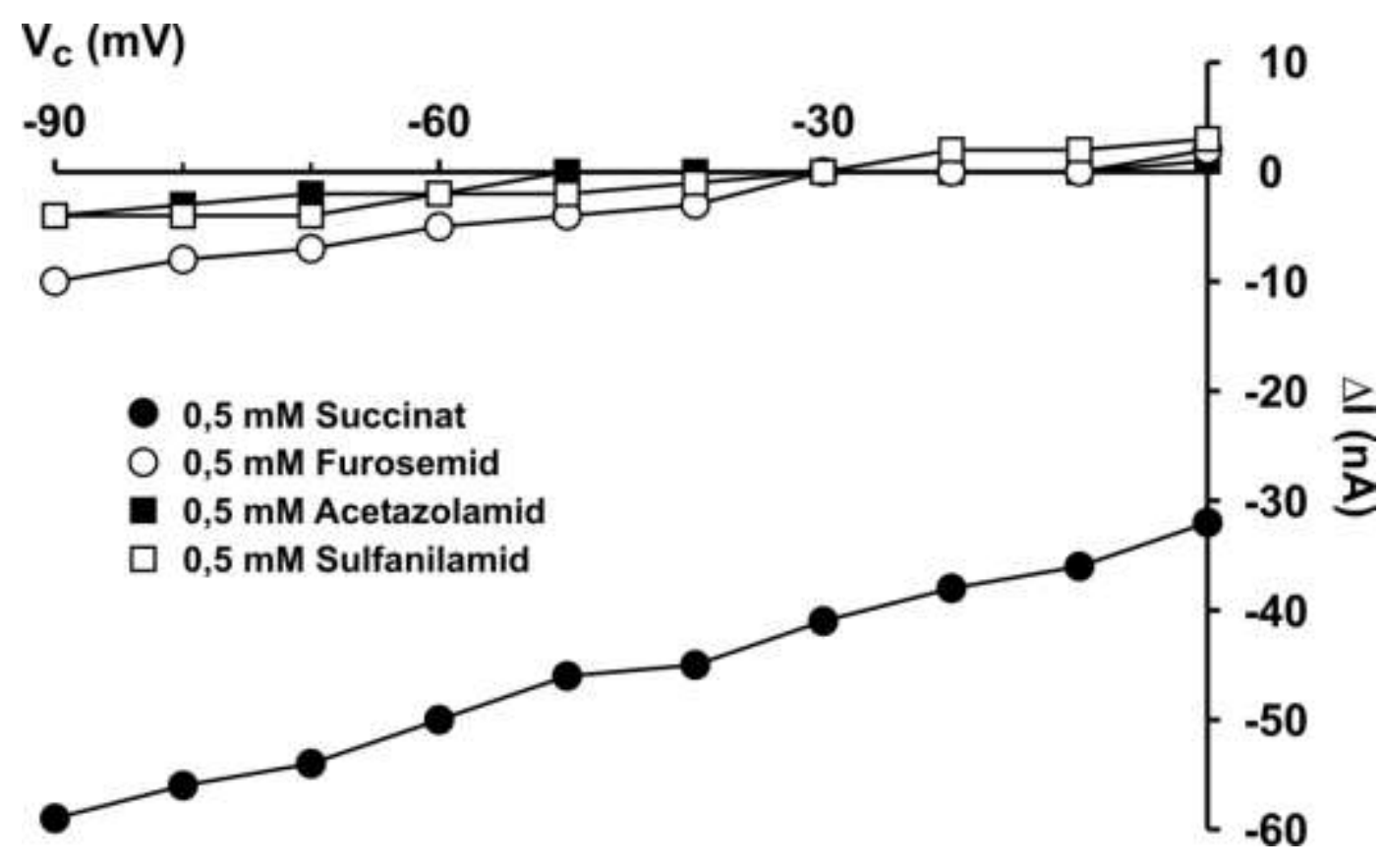

Abbildung 25: Interaktion von 0,5 mM Acetazolamid (schwarze Quadrate) und 0,5 mM Sulfanilamid (weiße Quadrate) mit dem hNaDC-3 im Vergleich zu 0,5 mM Furosemid (weiße Kreise) bzw. 0,5 mM Succinat (schwarze Kreise) dargestellt als Differentialströme $\Delta \mathrm{l}$. Erhebung der Daten aus Messungen an 7 hNaDC-3-exprimierenden Oozyten (3 Spendertiere), sowie 2 Kontrolloozyten von 2 Spendertieren. 


\section{Diskussion}

\subsection{Interaktion von Schleifendiuretika mit dem hNaDC-3}

Schleifendiuretika sind Diuretika die die renale Ausscheidung von Natrium, Kalium und Chlorid erhöhen und dadurch eine vermehrte Wasserausscheidung erzielen (GREGER 1999 und 2000, WANG $\mathrm{H}$ et al. 2000, SHANKAR und BRATER 2003, BAGSHAW et al. 2008). Auf Grund ihrer hohen Eiweißbindung erreichen Schleifendiuretika das tubuläre Nierenlumen und damit ihren Wirkort, den NatriumKalium-2Chlorid-Cotransporter (NKCC2) im dicken aufsteigenden Ast der Henle'schen Schleife, kaum durch glomeruläre Fitration, sondern hauptsächlich durch tubuläre Sekretion (PONTO und SCHOENWALD 1990, SHANKAR und BRATER 2003, HASANNEJAD et al. 2004). Erste Untersuchungen bezüglich der Transportmechanismen der Schleifendiuretika aus dem Blut in die proximale Tubuluszelle stellten Ullrich et al. 1989 anhand von Versuchen an der Rattenniere in situ an. Die Autoren konnten eine Hemmung der Aufnahme von Succinat über die basolaterale Membran durch Furosemid mit einer $K_{i}$ von 5,1 mM nachweisen (ULLRICH et al. 1989). In der Zwischenzeit konnte der für den renalen Transport von Dikarboxylaten (wie z.B. Succinat) zuständige Transporter, hNaDC-3, kloniert und funktionell charakterisiert werden. Der hNaDC-3 liegt in der basolateralen Membran der proximalen Tubuli (WANG et al. 2003) und dient hauptsächlich der Bereitstellung von $\alpha$-Ketoglutarat für die ebenfalls in der basolateralen Membran lokalisierten organischen Anionentransporter hOAT1 und hOAT3. (BURCKHARDT BC et al. 2002, DANTZLER 2002, MARKOVICH und MURER 2004, WANG $\mathrm{H}$ et al 2000).

In unseren Untersuchungen an $\mathrm{hNaDC}$-3-expirmierenden Oozyten konnten wir nun zunächst die von Ullrich gezeigte Interaktion des Furosemids mit dem hNaDC-3 sowohl anhand der Aufnahme von radioaktiv markiertem Succinat $\left(\left[{ }^{14} \mathrm{C}\right]\right.$ Succinat) als auch durch elektrophysiologische Untersuchungen bestätigen. Dabei zeigte sich in den Aufnahmeversuchen an hNaDC-3-exprimierenden Oozyten eine Reduktion des nachgewiesenen Transports von $\left[{ }^{14} \mathrm{C}\right]$ Succinat durch $1 \mathrm{mM}$ Furosemid um ca. $40 \%$, sowie eine $\mathrm{IC}_{50}$ von $2,2 \mathrm{mM}$ bei $-30 \mathrm{mV}$ durch Furosemid auf die Succinat-mediierten Einwärtsströme in den elektrophysiologischen Versuchen. 
Für die weitergehenden Untersuchungen zum Nachweis eines Transportes des Furosemids über hNaDC-3 wurde nur noch die Zwei-Elektroden-Klemmtechnik eingesetzt. Diese besitzt gegenüber den Versuchen zur Aufnahme mit radioaktivmarkierten Substanzen den Vorteil, dass hierbei an ein und derselben hNaDC-3exprimierenden Oozyte die Substrat-assoziierten Ströme mehrerer Substanzen miteinander verglichen werden können und somit der Faktor der biologischen Variabilität ausgeschaltet werden kann. Vorraussetzung für ein aussagekräftiges Ergebnis ist allerdings, dass diese Substanzen in einem elektrogenen Modus über den zu untersuchenden Transporter transloziert werden. Diese Bedingung muss bei den Versuchen zur Aufnahme mit radioaktiv-markierten Substanzen nicht gegeben sein, allerdings kann bei dieser Technik auch nicht die Aufnahme von zwei oder mehreren Substanzen an ein und derselben Oozyte miteinander verglichen werden. $\mathrm{Da}$ wir aber von einem Symport des zwei negative Ladungen besitzenden Furosemids mit $3 \mathrm{Na}^{+}$über den hNaDC-3 ausgingen, sollte und konnte eine Ladungsverschiebung über die Membran der Oozyte, die als Einwärtsstrom mittels der Zwei-Elektroden-Spannungsklemmtechnik nachgewiesen werden kann, gemessen werden.

Die in hNaDC-3-exprimierenden Oozyten nachgewiesenen Furosemid-induzierte Einwärtsströme waren allerdings besonders im Vergleich zu den an denselben Oozyten gemessenen Succinat-induzierten Einwärtsströmen sehr gering. Um daher einen weiteren Anhalt dafür zu erhalten, dass die Furosemid-induzierten Einwärtsströme durch einen Transport über den hNaDC-3 zustande kommen und nicht nur durch eventuelle „Leckströme" o.ä. vorgetäuscht sind, ersetzten wir Natrium in der ORI-Lösung durch $\mathrm{N}$-methyl-D-Glutamin. Dadurch sistierten die zuvor erzielten Einwärtsströme. Da der Transport von Stoffen über den hNaDC-3 streng natriumabhängig ist (KEKUDA et al. 1999, PAJOR 1995, PAJOR 2006, PAJOR et al. 2001, SEKINE et al. 1998, STEFFGEN et al. 1999, WANG H et al. 2000) konnte der Transport von Furosemid über den hNaDC-3 dadurch verifiziert werden.

Somit zeigte sich ein, wenn auch nur geringer, so doch eindeutiger spannungs- und natriumabhängiger Transport von Furosemid über den hNaDC-3 (graphisch aufgearbeitet in Abbildung 26). Einwärtsströme ähnlich geringer Amplitude konnten für Bumetanid und Etacrynsäure nachweisen werden. Allerdings lagen die für einen Transport notwenigen Mengen weit über den therapeutisch relevanten Dosierungen 
von 0,4 $\mu \mathrm{M}$ ungebunden vorliegenden Furosemids bzw. 0,2 $\mu \mathrm{M}$ Bumetanids (HASSANEJAD et al. 2004).

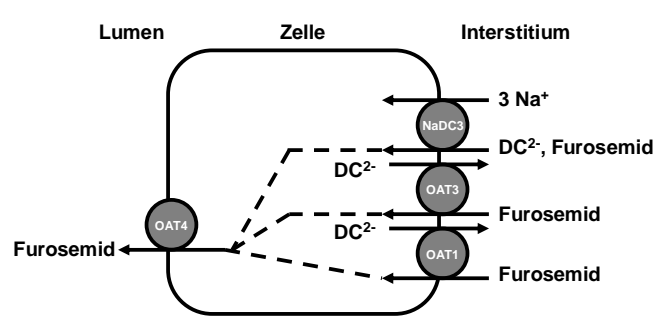

Abbildung 26: Schema der Sekretion des Furosemid vom Blut/Interstitium über die proximale Tubuluszelle in das Tubuluslumen. Die Aufnahme vom Blut in die Zelle erfolgt über die basolateral lokalisierten OAT1 und OAT3, sowie über den NaDC-3. Die Abgabe ins tubuläre Lumen erfolgt u.a. über den OAT 4.

In der klinischen Praxis sollten Furosemid bzw. Bumetanid also weder über den hNaDC-3 transportiert werden, noch in pharmakologischen Dosierungen auf Substanzen Einfluss nehmen, die über den hNaDC-3 transloziert werden (z.B. $\alpha$ Ketoglutarat). Da die OATs an NaDC-3 gekoppelt sind, wird auch bei pharmakologisch niedriger Dosierung der Schleifendiuretika, der Transport anderer Pharmaka, die über die OAT1 oder OAT3 ausgeschieden werden, nicht beeinflusst. Ungeklärt bleibt im Rahmen dieser Arbeit warum Schleifendiuretika erst ab Dosen im millimolaren Bereich über den hNaDC-3 transportiert werden und welche Transportmechanismen dann für die Translokation von Schleifendiuretika über die basolaterale Membran der proximalen Tubuluszelle zuständig sind. Ersteres kann zurzeit nicht beantwortet werden und bleibt ggf. Gegenstand weiterer Forschung. Bezüglich der zweitgenannten Frage konnte mittlerweile zum einen Anhand von Inihibtionsversuchen mit den radioaktiv markierten Substraten p-Aminohippurat (PAH) bzw. Estronsulfat (ES) (siehe Tabelle 5) und zum anderen durch direkten Nachweis einer Aufnahme von radioaktiv-markierten Schleifendiuretika gezeigt werden, dass die organischen Anionentransporter hOAT1 und hOAT3 für die Aufnahme der Schleifendiuretika über die basolaterale Membran in die proximale Tubuluszelle zuständig sind (HASANNEJAD et al. 2004, HAGOS et al. 2007). 


\begin{tabular}{|l|l|l|l|}
\hline Substanz & $\begin{array}{l}\text { hNaDC3*(Substrat- } \\
\text { mediierter Strom) }\end{array}$ & $\begin{array}{l}\text { OAT1** (Hemmung der } \\
\text { PAH-Aufnahme), } \\
\mathbf{I C}_{\mathbf{5 0}}(\boldsymbol{\mu M})\end{array}$ & $\begin{array}{l}\text { OAT3** (Hemmung } \\
\text { der ES-Aufnahme), } \\
\text { IC }_{\mathbf{5 0}}(\boldsymbol{\mu M})\end{array}$ \\
\hline Furosemid & $\sqrt{ }$ & $14-20$ & $1,7-7,31$ \\
\hline Bumetanid & $\sqrt{ }$ & 7,6 & 0,75 \\
\hline Etacrynsäure & $\sqrt{ }$ & 29,6 & 0,58 \\
\hline Acetazolamid & $\sqrt{ }$ & nicht getestet & 816 \\
\hline
\end{tabular}

Tabelle 5: Übersicht über die involvierten Transportsysteme für Schleifendiuretika; *diese Arbeit; **(BURCKHARDT G und BURCKHARDT BC 2011)

Interessant ist die Tatsache, dass die Transporter hOAT1 und hOAT3 eine deutlich höhere Affinität für Bumetanid (hOAT1 7,6 $\mathrm{M}$; hOAT3 0,75 $\mu \mathrm{M}$ ) und Furosemid (hOAT1 $18 \mu \mathrm{M}$; hOAT3 7,3 $\mu \mathrm{M}$ ) als für Torasemid (hOAT1 IC $5055 \mu \mathrm{M}$; hOAT3 IC ${ }_{50}$ $89 \mu \mathrm{M})$ aufweisen. Dies könnte zum einen die langsamere Aufnahme von Torasemid aus dem Blut in die Nierenzelle im Vergleich zu Furosemid und Bumetanid erklären und zum anderen bedeuten, dass ein weiterer Transporter in die Aufnahme des Torasemids vom Blut in die proximale Nierenzelle involviert ist. Da Torasemid im Gegensatz zu den Sulfonamidderivaten Furosemid und Bumetanid ein Pyridinsulfonylharnstoffderivat ist, verfügt es über andere chemische Eigenschaften und könnte daher ein besseres Substrat für den $\mathrm{hNaDC}-3$ sein.

Der Transport der Schleifendiuretika über die luminale Membran der proximalen Tubuluszelle ist zurzeit Gegenstand aktueller Forschung. Bisher scheinen hierfür hauptsächlich der OAT4 und der hNPT4 zuständig zu sein (HASANNEJAD et al. 2004, JUTABHA et. al 2010). Damit einhergehend wurden auch erste Erklärungen für die unter Schleifendiuretika auftretende Hyperurikämie gefunden, da der hNPT4 auch als Urattransporter identifiziert wurde und somit durch den gleichzeitigen Transport von Schleifendiuretika die renale Uratausscheidung über den hNPT4 gehemmt wird (JUTABHA et. al 2010).

Zusammenfassend lässt sich feststellen, dass der NaDC-3 nur einen geringen Beitrag zum Transport von Schleifendiuretika liefert. Die pharmakologisch im Blut 
gemessenen Konzentrationen der Schleifendiuretika liegen deutlich unter den in dieser Arbeit eingesetzten Konzentrationen, sodass der NaDC-3 im klinischen Alltag keine Rolle für den Transport von Schleifendiuretika spielen dürfte. Dies bestätigt das Bild des hNaDC-3, dass dem NaDC-3 in dem Transport von Medikamenten nur eine untergeordnete Rolle zukommt und dass seine physiologische Rolle hauptsächlich in der Bereitstellung des $\alpha$-Ketoglutarats für die organischen Anionentransportsysteme liegt.

Dazu passend zeigten sich bei den ergänzend durchgeführten Untersuchungen mit dem Carboanhydrase-Hemmstoff Acetazolamid und mit Sulfanilamid, Prototyp aller Sulfonamide, in den elektrophysiologischen Messungen nur sehr geringe Einwärtsströme. Insgesamt fielen die durch Acetazolamid und Sulfanilamid am hNaDC-3 hervorgerufenen Ströme noch deutlich geringer aus, als die durch Furosemid induzierten Einwärtsströme. Auch hier liegt die therapeutisch relevante Dosierung von 33,8 $\mu \mathrm{M}$ (HASANNEJAD et al. 2004) deutlich niedriger als die von uns benötigten Mengen an Substrat, um einen Transport zu erzielen.

Als verantwortlich für den basolateralen Transport von Acetazolamid in die proximale Nierenzelle konnte mittlerweile der hOAT1 identifiziert werden (HASANNEJAD et al. 2004 und Tab. 5)

\subsection{Wirkung von Lithium auf den hNaDC-3}

In der vorliegen Arbeit wurde nur ein geringer Einfluss von Lithium auf den Transport von Furosemid über den hNaDC-3 gefunden. Da eine Hemmung aber nur bis zu Klemmspannungen von ca. $-60 \mathrm{mV}$ zu erkennen ist und der hNaDC-3 in dem Transport von Furosemid keine entscheidene Rolle spielt, lassen unserer Versuche keine Rückschlüsse zu, warum die gleichzeitige Anwendung von Schleifendiuretika und Lithium zu einer erhöhten Gefahr einer Lithiumintoxikation führt. 


\section{Zusammenfassung}

Schleifendiuretika werden auf Grund ihrer hohen Eiweißbindung kaum glomerulär filtriert, sondern hauptsächlich in das Tubuluslumen der Niere sezerniert. Um zu untersuchen, ob dies durch Beteiligung des in der basolateralen Membran des Nierentubulus gelegenen, natriumabhängigen Dikarboxylat-Transporters (NaDC-3) geschieht, wurden an hNaDC-3-exprimierenden Oozyten sowohl Untersuchungen mit der Zwei-Elektroden-Spannungsklemmtechnik als auch Aufnahmeversuche mit radioaktiv markiertem Succinat $\left(\left[{ }^{14} \mathrm{C}\right]\right.$ Succinat) durchgeführt.

Die elektrophysiologischen Untersuchungen ergaben eine Hemmung des Succinatassoziierten Stroms durch Furosemid mit einer $\mathrm{IC}_{50}$ von $2,2 \mathrm{mM}$ in $\mathrm{hNaDC}-3$ exprimierenden Oozyten. Ergänzend durchgeführte Aufnahmeversuche mit $\left[{ }^{14} \mathrm{C}\right]$ Succinat bestätigten dieses Ergebnis. Dadurch konnte eine Interaktion von Furosemid mit dem hNaDC-3 gesichert werden.

Anschließend gelang es durch elektrophysiologische Messungen, einen Furosemidinduzierten Einwärtsstrom an hNaDC-3-exprimierenden Oozyten nachzuweisen. Dieser ergibt sich durch den Symport des zwei negative Ladungen besitzenden Furosemids mit $3 \mathrm{Na}^{+}$über den hNaDC-3.

Ersetzt man Natrium in der ORI-Lösung durch $\mathrm{N}$-methyl-D-Glucamin, lassen sich in elektrophysiologischen Messungen keine signifikanten Ströme mehr nachweisen, wodurch der Transport von Furosemid über den hNaDC-3 verifiziert werden konnte.

Untersuchungen mit den Schleifendiuretika Etacrynsäure und Bumetanid zeigen ähnliche Einwärtsströme bei Messungen an hNaDC-3- exprimierenden Oozyten wie die Untersuchungen mit Furosemid.

Insgesamt lässt sich somit eindeutig ein Transport von Furosemid und strukturell verwandten Schleifendiuretika über den $\mathrm{hNaDC}-3$ konstatieren. Die hierfür benötigten Konzentrationen liegen allerdings weit über den therapeutisch relevanten Dosierungen und bestätigen die Ergebnisse, die den hOAT1 und hOAT3 als 
Haupttransportweg für Schleifendiuretika vom Blut in die proximale Nierenzelle gezeigt haben.

Eine klinisch relevante Wechselwirkung von Lithium und Furosemid im Rahmen einer Interaktion mit dem hNaDC-3 konnte in dieser Arbeit nicht gezeigt werden.

Ergänzende Untersuchungen an hNaDC-3-exprimierenden Oozyten mit Acetazolamid und Sulfanilamid wiesen in den elektrophysiologischen Messungen nur minimale Einwärtsströme auf, die den $\mathrm{hNaDC}-3$ als relevanten Transportweg für diese Substanzen ausschließt.

Einige Experimente dieser Arbeit sind publiziert worden in: Müller I, Hagos $Y$, Burckhardt G, Burckhardt BC. Interaction of furosemide with the human sodiumdependent Dikarboxylate transporter (hNaDC-3). Lettr in Drug Design Discov 2: 567570,2005 


\section{Literaturverzeichnis}

Akin I, Rauchhaus M, Kische S, Wenzel R, Schmidt H, Nienaber C, Ince H (2009): Einsatz von Diuretika bei der akut dekompensierten Herzinsuffizienz. Intensivmed und Notfallmed $\underline{46}, 399-406$

Anzai N, Jutabha P, Kanai Y, Endou H (2005): Integrated physiology of proximal tubular organic anion transport. Curr Opin Nephrol Hypertens 14, 472-79

Anzai N, Kanai $\mathrm{Y}$, Endou $\mathrm{H}$ (2006): Organic anion transporter family: current knowledge. J Pharmacol Sci 100, 411-26

Babu E, Takeda M, Narikawa S, Kobayashi Y, Enomoto A, Tojo A, Cha SH, Sekine T, Sakthisekaran D, Endou H (2002): Role of human organic anion transporter 4 in the transport of ochratoxin A. Biochim Biophys Acta $\underline{1590}$, 64-75

Bagshaw SM, Bellomo R, Kellum JA (2008): Oliguria, volume overload, and loop diuretics. Crit Care Med $\underline{36}, 172-78$

Bahn A, Hagos Y, Reuter S, Balen D, Brzica H, Krick W, Burckhardt BC, Sabolic I, Burckhardt $G$ (2008): Identification of a new urate and high affinity nicotinate transporter, hOAT10 (SLC22A13). Biol Chem 283, 16332-41

Bauer M, Whybrow PC, Angst J, Versiani M, Möller HJ (2004): World Federation of Societies of Biological Psychiatry (WFSBP) Guidelines for Biological Treatment of Unipolar Depressive Disorders, Part 2: Maintenance treatment of major depressive disorder and treatment of chronic depressive disorders and subthreshold depressions. World J Biol Psychiatry $\underline{3}, 69-86$

Bianco S, Vaghi A, Robuschi M, Pasargiklian M (1988): Prevention of exerciseinduced bronchoconstriction by inhaled frusemide. Lancet 1988, 2, 252-55 
Bhure UN, Bhure SU, Bhatt BM, Mistry S, Pednekar SJ, Chari VV, Desai SA, Joshi JM, Paidhungat AJ (2009): Lung epithelial permeability and inhaled furosemide: added dimensions in asthmatics. Ann Nucl Med 233, 549-57

Brater DC (1998): Diuretic Therapy. N Engl J Med $\underline{339}$, 387-95

Burckhardt BC, Burckhardt G (2003): Transport of organic anions across the basolateral membrane of proximal tubule cells. Rev Physiol Biochem Pharmacol $\underline{146}$, 95-158

Burckhardt BC, Drinkuth B, Menzel C, König A, Steffgens J, Wrigh SH, and Burckhardt G (2002): The Renal Na-Dependent Dikarboxylate Transporter, NaDC-3, Translocates Dimethyl- and Disulfhydryl-Compounds and Contributes to Renal Heavy Metal Detoxification. J Am Soc Nephrol 13, 2628-2638

Burckhardt BC, Lorenz J, Burckhardt G, Steffgen J. (2004): Interactions of benzylpenicillin and non-steroidal anti-inflammatory drugs with the sodium-dependent Dikarboxylate transporter NaDC-3. Cell Physiol Biochem 14, 415-24

Burckhardt BC, Lorenz J, Kobbe C (2005): Substrate specificity of the human renal sodium Dikarboxylate cotransporter, $\mathrm{hNaDC}-3$, under voltage-clamp conditions. Am J Physiol Renal Physiol 288, 792-99

Cha S, Sekine T, Fukushima J, Kanai Y, Kobayashi Y, Goya T Endou H (2001): Identification and Characterization of Human Organic Anion Transporter 3 Expressing Predominantly in the Kidney. Mol Pharmacol $\underline{59}$, 1277-86

Chen X, Tsukaguchi H, Chen XZ, Berger UV, and Hediger MA (1999): Molecular and functional analysis of SDCT2, a novel rat sodium-dependent Dikarboxylate transporter. J Clin Invest 103, 1159-68

Dantzler WH (2002): Renal organic anion transport: a comparative and cellular perspective. Biochem Biophys Acta 1566, 169-81 
Dantzler WH, Wright SH (2003): The molecular and cellular physiology of basolateral organic anion transport in mammalian renal tubules. Biochim Biophys Acta $\underline{1618}$, $185-93$

Dawid IB, Sargent TD (1988): Xenopus laevis in developmental and molecular biology. Science $\underline{240}, 1443-48$

Dresser MJ, Leabman MK, Giacomini KM (2001): Transporters involved in the elimination of drugs in the kidney: organic anion transporters and organic cation transporters. J Pharm Sci $\underline{90}$, 397-421

Dumont J (1972): Oogenesis in Xenopus laevis (Daudin). I. Stages of oocyte development in laboratory maintained animals. J Morphol 136, 153-79

Fülgraff G, Palm D : Pharmakotherapie, 11. Auflage; Urban und Fischer Verlag, München/Jena 2001

Geck P, Pietrzyk C, Burckhardt BC, Pfeiffer B (1980): Electrically silent cotransport on $\mathrm{Na}+, \mathrm{K}+$ and $\mathrm{Cl}$ - in Ehrlich cells. Biochim Biophys Acta $\underline{600}, 432-47$

Gerbes A, Gülberg V (2004): Diagnosis and treatment of ascites. Dtsch Med Wochenschr $\underline{129}$, 63-65

Greger R (1988): Chloride transport in thick ascending limb, distal convolution, and collecting duct. Annu Rev Physiol $\underline{50}, 111-22$

Greger R (1997): How does the macula densa sense tubule function? Nephrol Dial Transplant 12, 2215-17

Greger R (1999): New insights into the molecular mechanism of the action of diuretics. Nephrol Dial Transplant 14, 536-40

Greger R (2000): Physiology of renal sodium transport. Am J Med Sci 319, 51-62 
Greger R, Schlatter E (1983): Cellular mechanism of the action of loop diuretics on the thick ascending limb of Henle's loop. Klin Wochenschr $\underline{61}, 1019-27$

Hagos Y, Andrew Bahn, Stefan V. Vormfelde, Jürgen Brockmöller and Gerhard Burckhardt (2007): Torasemide Transport by Organic Anion Transporters Contributes to Hyperuricemia. J Am Soc Nephrol 18, 3101-09

Hagos Y, Krick W, Braulke T, Mühlhausen C, Burckhardt G, Burckhardt BC (2008): Organic anion transporters OAT1 and OAT4 mediate the high affinity transport of glutarate derivatives accumulating in patients with glutaric acidurias. Pflugers Arch $\underline{457}, 223-31$

Hasannejad H, Takeda M, Taki K, Shin HJ, Babu E, Jutabha P, Khamdang S, Aleboyeh M, Onozato ML, Tojo A. (2004):Interactions of Human Organic Anion Transporters with Diuretics. J Pharmacol Exp Ther $\underline{308}$, 1021-29

Ho K, Power B (2010): Benefits and risks of furosemide in acute kidney injury. Anaesthesia $\underline{65}, 283-93$

Hosoyamada M, SekineT, Kanai Y, Endou H (1999): Molecular cloning and functional expression of a multispecific organic anion transporter from human kidney. Am J Physiol Renal Physiol 276, 122-28

Hodgkin AL, Huxley AF, Katz B (1952): Measurement of current-voltage relations in the membrane of the giant axon of Loligo. J of Physiol $\underline{116}, 424-448$

Joseph SM, Cedars AM, Ewald GA, Geltman EM, Mann DL (2009): Acute Decompensated Heart Failure. Tex Heart Inst J $\underline{36}$, 510-20

Jutabha P, Anzai N, Kimura T, Taniguchi A, Urano W, Yamanaka H, Endou H, Sakurai $H$ (2011): Functional analysis of human sodium-phosphate transporter 4 (NPT4/SLC17A3) polymorphisms. J Pharmacol Sci $\underline{115}$, 249-53

Kapoor JR, Perazella MA. (2007): Diagnostic and therapeutic approach to acute decompensated heart failure. Am J Med 120, 121-27 
Kekuda R, Wang H, Huang W, Pajor AM, Leibach FH, Devoe LD, Prasad PD, Ganapathy V (1999): Primary structure and functional characteristics of a mammalian sodium-coupled high affinity Dikarboxylate transporter. J Biol Chem $\underline{274}, 3422-29$

Kiil F (2002): Analysis of the tubuloglomerular feedback mechanism in renal autoregulation. Acta Physiol Scand 174, 357-66

Kimura H, Takeda M, Narikawa S, Enomoto A, Ichida K, Endou H (2002): Human organic anion transporters and human organic cation transporters mediate renal transport of prostaglandins. Pharmacol Exp Ther 301, 293-98

Kobayashi Y, Ohshiro N, Sakai R, Ohbayashi M, Kohyama N, Yamamoto T (2005): Transport mechanism and substrate specificity of human organic anion transporter 2 hOat2 [SLC22A7]. J Pharm Pharmacol $\underline{57}$, 573-78

Koepsell H, Endou H (2004): The SLC22 drug transporter family. Pflugers Arch 447, 666-76

Kojima R, Sekine T, Kawachi M, Cha SH, Suzuki Y, Endou H (2002): Immunolocalization of multispecific Organic Anion Transporters, OAT1, OAT2, and OAT3, in rat kidney. J Am Soc Nephrol $\underline{13}$, 848-57

Lameire N, Vanholder R, Van Biesen W (2002): Loop diuretics for patients with acute renal failure: helpful or harmful? JAMA $\underline{288}, 2599-601$

LeGrand S, Leskuski D, Zama I (2008): Narrative review: furosemide for hypercalcemia: an unproven yet common practice. Ann Intern Med 149, 259-63

Markovich D, Murer H (2004): The SLC13 gene family of sodium sulphate/ carboxylate cotransporters. Eur J Physiol $\underline{447}, 594-602$ 
Mühlhausen C, Burckhardt BC, Hagos Y, Burckhardt G, Keyser B, Lukacs Z, Ullrich $\mathrm{K}$, Braulke $\mathrm{T}$ (2008): Membrane translocation of glutaric acid and its derivatives. J Inherit Metab Dis. 2008 Apr 4 [Epub ahead of print]

Müller I, Hagos Y, Burckhardt G, Burckhardt BC (2005): Interaction of furosemide with the human sodium-dependent Dikarboxylate transporter (hNaDC-3). Lett Drug Design Discov $\underline{2}, 567-570$

Nieth H, Schollmeyer P (1966): Substrate-utilization of the human kidney. Nature 209, 1244-45

Okamoto N, Aruga S, Matsuzaki S, Takahashi S, Matsushita K, Kitamura T (2007): Associations between renal sodium-citrate cotransporter (hNaDC-1) gene polymorphism and urinary citrate excretion in recurrent renal calcium stone formers and normal controls. Int J Urol $\underline{14}, 344-49$

Oshiro N, Pajor A (2005): Functional characterization of high-affinity $\mathrm{Na}(+)$ /Dikarboxylate cotransporter found in Xenopus laevis kidney and heart. Am J Physiol Cell Physiol 289, C1159-68

Pajor A (1995): Sequence and functional characterization of a renal sodium/Dikarboxylate cotransporter. J Biol Chem $\underline{270}$, 5779-85

Pajor A (1999): Sodium-coupled transporters for Krebs cycle intermediates Annu Rev Physiol 61, 663-82

Pajor A (2006): Molecular properties of the SLC13 family of Dikarboxylate and sulfate transporters. Pflugers Arch $\underline{451}, 597-605$

Pajor A, Sun N (1996): Functional differences between rabbit and human $\mathrm{Na}(+)-$ Dikarboxylate cotransporters, NaDC-1 and hNaDC-1. Am J Physiol 271, F1093-99 
Pajor AM, Hirayama BA, Loo DD (1998): Sodium and lithium interactions with the $\mathrm{Na}+$ /Dicarboxylate cotransporter. Biol Chem $\underline{273}, 18923-9$.

Pajor A, Gangula R, and Yao N (2001): Cloning and functional characterization of a high-affinity $\mathrm{Na}+/$ Dikarboxylate cotransporter from mouse brain. Am J Physiol Cell Physiol $\underline{280}, 1215-23$

Ponto L, Schoenwald R (1990): Furosemide (frusemide). A pharmacokinetic / pharmacodynamic review (Part II). Clin Pharmacokinet 18, 460-67

Pritchard JB, Miller DS (1991): Comparative insights into the mechanisms of renal organic anion and cation secretion. Am J Physiol 261, 1329-40

Pritchard JB, Miller DS (1993): Mechanisms mediating renal secretion of organic anions and cations. Physiol Rev $\underline{73}, 765-96$

Ralston S, Coleman R, Fraser W, Gallagher S, Hosking D, lqbal J, McCloskey E Sampson D (2004): Medical management of hypercalcemia. Calcif Tissue Int $\underline{74}, 1$ 11

Rizwan AN, Burckhardt G (2007): Organic Anion Transport of the SLC22 Family: Biopharmaceutical, Physiologiacal, and Pathological Roles. Pharm Res $\underline{24}$, 450-70

Robertson E, Rankin G (2006): Human renal organic anion transporters: Characteristics and contributions to drug and drug metabolite excretion. Pharmacol Ther $\underline{109}, 399-412$

Sampath S, Moran J, Graham P, Rockliff S, Bersten A, Abrams K (2007): The efficacy of loop diuretics in acute renal failure: assessment using Bayesian evidence synthesis techniques. Crit Care Med. 35, 2516-24

Sekine T, Endou H (2009): Children's toxicology from bench to bed--Drug-induced renal injury (3): Drug transporters and toxic nephropathy in childhood. J Toxicol Sci $\underline{34}, 259-65$ 
Sekine T, Cha SH, Hosoyamada M, Kanai Y, Watanabe N, Furuta Y, Fukuda K, Igarashi T, Endou H (1998): Cloning, functional characterization, and localization of a rat renal Na+-Dikarboxylate transporter. Am J Physiol 275, 298-305

Shankar SS, Brater DC (2003): Loop diuretics: from the Na-K-2Cl transporter to clinical use. Am J Physiol Renal Physiol 284, 11-21

Sproule B (2002): Lithium in bipolar disorder: can drug concentrations predict therapeutic effect? Clin Pharmacokinet $\underline{41}, 639-60$

Steffgen J, Burckhardt BC, Langenberg C, Kühne L, Müller GA, Burckhardt G, Wolff NA (1999): Expression cloning and characterization of a novel sodium-Dikarboxylate cotransporter from winter flounder kidney. J Biol Chem 274, 20191-96

Stellmer F, Keyser B, Burckhardt BC, Koepsell H, Streichert T, Glatzel M, Jabs S, Thiem J, Herdering W, Koeller DM (2007): 3-Hydroxyglutaric acid is transported via the sodium-dependent Dikarboxylate transporter NaDC-3. J Mol Med $\underline{85}$, 763-70

Taft D and Sweeney K (1995): The influence of protein binding on the elimination of acetazolamide by the isolated perfused rat kidney: Evidence of albumin-mediated tubular secretion. J Pharmacol Exp Ther 274, 752-60

Taft DR, Chapron DJ, Fournier DJ and Sweeney KR (1996): Concentrationdependent tubular secretion of acetazolamide and its inhibition by salicylic acid in the isolated perfused rat kidney. Drug Metab Dispos 24, 456-61

Ullrich KJ (1994): Specificity of transporters for 'organic anions' and 'organic cations' in the kidney. Biochim Biophys Acta 1197, 45-62

Ullrich KJ (1997): Renal Transporters for Organic Anions and Organic Cations. Structural Requirements for Substrates. J Membr Biol 158, 95-107

Ullrich KJ, Rumrich G (1988): Contraluminal transport systems in the proximal renal tubule involved in secretion of organic anions. Am J Physiol 254, 453-62 
Ullrich KJ, Rumrich G (1993): Renal transport mechanisms for xenobiotics: chemicals and drugs. Clin Investig $\underline{71}, 843-48$

Ullrich KJ, Rumrich G, Klöss S (1989): Contraluminal organic anion and cation transport in the proximal renal tubule: $\mathrm{V}$. Interaction with sulfamoyl- and phenoxy diuretics, and with beta-lactam antibiotics. Kidney Int $\underline{36}, 78-88$

Wagner CA, Friedrich B, Setiawan I, Lang F, Broer S (2000): The use of Xenopus laevis oocytes for the functional characterization of heterologously expressed membrane proteins. Cell Physiol Biochem 10, 1-12

Wang D, Gottlieb S (2008): Diuretics: still the mainstay of treatment. Crit Care Med $\underline{36}, 89-94$

Wang H, Fei YJ, Kekuda R, Yang-Feng TL, Devoe LD, Leibach FH, Prasad PD, Ganapathy ME (2000): Structure, function and genomic organization of human $\mathrm{Na}^{+}-$ dependent high-affinity Dikarboxylate transporter. Am J Physiol Cell Physiol $\underline{278}$, 1019-30

Wilcox CS (2002): New insights into diuretic use in patients with chronic renal disease. Am Soc Nephrol 13, 798-805

Yano I, Takayama A, Takano M, Inatani M, Tanihara H, Ogura Y, Honda Y, Inui K (1998): Pharmacokinetics and pharmacodynamics of acetazolamide in patients with transient intraocular pressure elevation. Eur J Clin Pharmacol 54, 63-68

Zuckerman J, Assimos D, Assismos BS (2009): Hypocitraturia: Pathophysiology and Medical Management. Rev Urol 11, 134-44 


\section{Abkürzungsverzeichnis}

\begin{tabular}{|c|c|}
\hline A & Ampere \\
\hline$\alpha-K G^{2-}$ & Alphaketoglutarat \\
\hline ANV & Akutes Nierenversagen \\
\hline ATP & Adenosintriphosphat \\
\hline ATPase & Natrium-Kalium-Pumpe \\
\hline bzw. & Beziehungsweise \\
\hline${ }^{\circ} \mathrm{C}$ & Grad Celsius \\
\hline ca. & Circa \\
\hline $\mathrm{Ca}^{2+}$ & Calcium \\
\hline $\mathrm{CaCl}_{2}$ & Calciumchlorid \\
\hline $\mathrm{cm}$ & Z?entimeter \\
\hline CRNA & copy Ribonukleinsäure \\
\hline$\Delta$ & Delta \\
\hline $\mathrm{dpm}$ & decays per minute \\
\hline et al. & et altera \\
\hline $\mathrm{g}$ & Gramm \\
\hline h & Stunde \\
\hline HEPES & N - 2-Hydroxyäthylpiperazin - N’-2-Äthansulfonsäure \\
\hline $\mathrm{H} 2 \mathrm{O}$ & Wasser \\
\hline hOAT & organischer Anionen-Transporter des Menschen \\
\hline$I \max$ & maximal induzierbarer Strom \\
\hline $\mathrm{L} / \mathrm{d}$ & Liter am Tag \\
\hline $\mathrm{K}^{+}$ & Kalium \\
\hline $\mathrm{K}_{\mathrm{i}}$ & Dissoziationskonstante (eines Inhibitors bei der Enzymkinetik) \\
\hline $\mathrm{M}$ & Molar \\
\hline $\mathrm{Mg}^{2+}$ & Magnesium \\
\hline$\mu g$ & Mikrogramm \\
\hline$\mu \mathrm{l}$ & Mikroliter \\
\hline$\mu \mathrm{M}$ & Mikromol \\
\hline$\mu \mathrm{S}$ & Mikrosiemens \\
\hline $\mathrm{mg}$ & Milligramm \\
\hline $\mathrm{ml}$ & Milliliter \\
\hline $\mathrm{mM}$ & $\mathrm{mmol} / \mathrm{l}$ \\
\hline $\mathrm{Mm}$ & Millimeter \\
\hline $\mathrm{mV}$ & Millivolt \\
\hline $\mathrm{nA}$ & Nanoampere \\
\hline $\mathrm{Na}^{+}$ & Natrium \\
\hline $\mathrm{NaCl}$ & Natriumchlorid \\
\hline $\mathrm{NaDC}$ & Natrium-Dikarboxylat-Cotransporter \\
\hline $\mathrm{nl}$ & Nanoliter \\
\hline OAT & organischer Anionen-Transporter \\
\hline ORi & Oozyten-Ringer \\
\hline $\mathrm{PAH}$ & p-Aminohippurat \\
\hline
\end{tabular}




\begin{tabular}{|l|l|}
\hline$R N S$ & Ribonukleinsäure \\
\hline S.o. & Siehe oben \\
\hline Tris & Trishydroxymethylaminomethan \\
\hline U.a. & unter anderem \\
\hline$V_{c}$ & Kommandospannung \\
\hline$V_{m}$ & Membranspannung \\
\hline Z.B. & Zum Beispiel \\
\hline
\end{tabular}




\section{Danksagung}

Bedanken möchte ich mich sehr herzlich bei allen Personen, die mich bei meiner Dissertationserstellung unterstützt haben.

Insbesondere gilt mein Dank meiner Betreuerin Frau Professor Dr. phil. nat. B.C. Burckhardt, die mit viel Geduld, Mühe und konstruktiver Kritik die Fertigstellung meiner Dissertation begleitet hat und jederzeit für Rückfragen zur Verfügung stand. Ebenso danken möchte ich Frau Irmgard Markmann, die sich viel Zeit genommen hat, um mir die notwendigen praktischen Fähigkeiten $\mathrm{zu}$ vermitteln und mich während des experimentellen Teils der Arbeit unterstützt hat. 


\section{Lebenslauf Ingo Sebastian Müller}

Am 18.01.1978 wurde ich als Sohn von Eva Grosse, geb. Sauerland, und Ullrich Müller in Marburg geboren.

Nach dem Besuch der Albani Grundschule in Göttingen von 1984 bis 1988 folgten 2 Jahre auf der Orientierungsstufe Lutherschule. 1990 kam ich auf das Max-PlanckGymnasium in Göttingen, wo ich 1997 meine Hochschulreife erlangte. Auf Grund einer Berufung in die U18 Nationalmannschaft im Bereich Mittel- und Langstrecke konnte ich 13 Monate als Zivildienstleistender in einer Sportförderstelle im ASC Göttingen absolvieren. Anschließend nahm ich zum WS 1998 das Studium der Humanmedizin an der Georg-August-Universität in Göttingen auf. Nach dem erfolgreichen Bestehen der ärztlichen Vorprüfung im August 2000 und des ersten Abschnittes der ärztlichen Prüfung im August 2001 folgten zwei Semester an der Universität Miguel Hernandez (Elche/Spanien) als Socrates-Stipendiant.

Ein Jahr nach meiner Rückkehr nach Göttingen begann ich im August 2003 mit dem experimentellen Teil meiner vorliegen Doktorarbeit in der Abteilung für Vegetative Physiologie und Pathophysiologie. Im März 2005 konnte ich den zweiten Teil der ärztlichen Prüfung erfolgreich ablegen und begann anschließend mit dem Praktischen Jahr. In dieser Zeit durchlief ich die Abteilungen für Innere Medizin (Prof. Dr. Katschinski), für Allgemein-und Viszeralchirurgie (Prof. Dr. Frey) im DIAKO in Bremen, sowie die Abteilung für Orthopädie (Prof. Dr. Friederich) im Kantonspital Bruderholz (Schweiz). Nach dem erfolgreichen Bestehen des dritten Abschnittes der ärztlichen Prüfung im April 2006 und Erlangen der Approbation begann ich die Facharztausbildung als Assistenzarzt in der Inneren Abteilung des Kreiskrankenhauses Osterholz-Scharmbeck. Nach der Geburt meins Sohnes OleFinjan Mertens im Januar 2008 unterbrach ich diese Ausbildung auf Grund von 9 Monaten Erziehungsurlaub (Juni 2008 - März 2009). Seit März 2009 arbeite ich wieder als Assistenzarzt in der Inneren Abteilung im Kreiskrankenhaus OsterholzScharmbeck. Im Dezember 2010 wurde das zweite gemeinsame Kind von Tabea Mertens und mir, Lenja Zoe Mertens, geboren. 